\title{
ACUMULAÇÃO DE CARBONO EM LAGOS AMAZÔNICOS COMO INDICADOR DE EVENTOS PALEOCLIMÁTICOS E ANTRÓPICOS
}

Renato Campello Cordeiro', Patrícia Florio Moreira Turcq2, Bruno Jean Turcq2, Luciane Silva Moreira $^{l}$, Rodrigo de Carvalho Rodrigues ${ }^{1}$, Renata Lima da Costa ${ }^{1}$, Abdelfetthah Sifeddine ${ }^{2}$ \& Francisco Fernando Lamego Simões Filho ${ }^{3}$

${ }^{1}$ Programa de Geoquímica, Universidade Federal Fluminense, Instituto de Quimica, $5^{\circ}$ andar, Centro, Niteroi, RJ, Brail. CEP: $24020-007$.

${ }^{2}$ Institute de Recherche pour le Development, 32 rue HenriVaragnat, 93143, Bondy, Cedex, France

${ }^{3}$ Instituto de Radiometria e Proteção, Conselho Nacional de Energia Nuclear.

*E-mail: rccordeiro@geoq.uff.br

\section{RESUMO}

A biota terrestre é considerada como um sumidouro de carbono atmosférico. As florestas tropicais apresentam um importante papel nesta assimilação, porém pouco ainda se sabe sobre o papel dos sistemas aquáticos continentais neste processo de acumulação bem como sua relação com as mudanças paleoclimáticas. Portanto, o objetivo deste artigo consiste em reunir os principais trabalhos realizados em lagos amazônicos, a fim de evidenciar a participação dos sistemas aquáticos amazônicos no acúmulo de carbono em função de mudanças paleoclimáticas e antrópicas na Amazônia. Para este estudo foram escolhidos três sistemas lacustres distintos: o primeiro consiste nos lagos de várzea Santa Ninha e Acarabixi, caracterizados por sofrerem influência direta do ciclo hidrológico do Rio Amazonas e Rio Negro respectivamente. O segundo engloba os lagos isolados da dinâmica fluvial amazônica, que apesar de serem pouco extensos em área tem um papel importante no que tange ao entendimento dos processos paleoclimáticos na Amazônia. Foram abordados então os seguintes registros: Lagoa da Pata (AM), Lago Caracaranã (RR), Lago CSN N4 Carajás (PA), Lago de campos inundados em Humaitá (AM). Como exemplo de sistema que recebe influência da atividade antrópica foi estudado barragem na região de intensa mudança do uso da terra em Alta Floresta (MT). Através de diferentes indicadores paleoambientais e ambientais (datações dos diferentes ecossistemas fluviais amazônicos por ${ }^{210} \mathrm{~Pb}$ e ${ }^{14} \mathrm{C}$, concentração de carbono orgânico, relação $\mathrm{C} / \mathrm{N}$, análise da deposição de partículas de carvão, $\delta^{13} \mathrm{C}, \delta^{15} \mathrm{~N}$, derivados de clorofila, determinação mineralógica, determinação de mercúrio e cálculo de taxas de acumulação de carbono) foram reconstruídas as condições ambientais pretéritas e suas implicações no funcionamento Os lagos de várzea Santa Ninha e Acarabixi apresentaram elevadas taxas de acumulação de carbono, chegando a atingir valores superiores a $400 \mathrm{~g} / \mathrm{m}^{2} /$ ano. Já os lagos isolados apresentaram fluxos mais reduzidos, onde raramente encontraram-se registros que ultrapassaram os $20 \mathrm{~g} / \mathrm{m}^{2} / \mathrm{ano}$. O maior valor de acumulação de carbono foi observado em de barragem em área de intensa mudança do uso da terra em Alta Floresta (MT). A acumulação de carbono alcança o maior fluxo de $433 \mathrm{~g} / \mathrm{m}^{2} /$ ano. Estes dados revelam uma importante participação de diferentes ambientes lacustres amazônicos na acumulação de carbono, que apresentou-se susceptível à alteração climática que ocorreu nos últimos milênios.

Palavras-chave: Acúmulo de carbono. lagos de várzea, lagos isolados, Amazônia, mudanças paleoclimáticas.

\section{ABSTRACT}

CARBON ACUMULATION IN AMAZON LAKES AS INDICATORS OF ANTROPIC AND PALEOCLIMATIC EVENTS. Land biota is regarded as a natural sink for atmospheric carbon. Tropical forests have an important role in this assimilation, but little is known about the role of continental aquatic systems in the process of carbon sequestration and its relationship with paleoclimatic changes. The objective of the present article is to bring together the main studies with Amazon lakes in order to highlight the participation of aquatic systems in the local accumulation of carbon and the participation of human-made and paleoclimatic changes in the Amazon in different time scales. Three different lake systems were analysed: the lowland lakes of Santa Ninha and Acarabixi, which are respectively directly influenced by the hydrological cycles of Amazon and Negro rivers, and some lakes that are isolated from the effects of the dynamics of Amazon rivers (which 
despite their little size play an important role in understanding the local palaeoclimatic processes). Records from the following locations were addressed: lake Pata (Amazon), lake Caracaranã (Roraima), lake CSN N4 Carajás (Pará), and a lake over a flooded field at Humaitá (Amazon). As an example of a system under anthropogenic influence, a dam in a region of intense alternate land usage at Alta Floresta (Mato Grosso) was studied. The past environmental conditions and their effect over the way the different Amazon river ecosystems work nowadays were estimated using a number of palaeoenvironmental indicatirs: chronological analyses by ${ }^{210} \mathrm{~Pb}$ and ${ }^{14} \mathrm{C}$, organic carbon concentration, $\mathrm{C} / \mathrm{N}$ ratio, determination of chlorophyll derivates, analysis of the deposition of charcoal particles, $\delta^{15} \mathrm{~N}$ and $\delta^{13} \mathrm{C}$, and accumulation rates of mercury, minerals , and carbon. The lowland lakes Santa Ninha and Acarabixi presented high carbon accumulation rates of over $400 \mathrm{~g} / \mathrm{m}^{2} / \mathrm{yr}$, while the isolated lakes presented lower carbon accumulation rates, records rarely exceeding $20 \mathrm{~g} / \mathrm{m}^{2} / \mathrm{yr}$. carbon accumulation rates between 10580 to 10550 cal.yr. B.P. in lake Acarabixi lake were the highest, reaching $462 \mathrm{~g} /$ $\mathrm{m}^{2} / \mathrm{yr}$, being its peak restricted to a brief period that dis not coincide with the peaks of Várzea of Curuaí. The carbon accumulation rate of Acarabixi is similar to the maximum carbon accumulation rate of the artificial barrier in the intense land use change area in Alta Floresta (MT). These data indicate that the different Amazon lake environments are important in the carbon accumulation rates, which may have altered because of the climate changes of the recent millennia.

Keywords: Carbon acumulation, lowland lakes, isolated lakes, Amazon, paleoclimatic changes.

\section{INTRODUÇÃO}

O interesse crescente da comunidade científica pelos assuntos referentes a mudanças globais, incrementa a necessidade do desenvolvimento de estudos paleoecológicos em regiões tropicais e equatoriais. Isto porque existem poucos estudos sobre como os ecossistemas florestais tropicais reagiram a mudanças do clima no passado e entender está dinâmica pode auxiliar na compreensão de como os sistemas florestais poderão reagir às futuras mudanças climáticas.

A seqüência e a natureza dos processos superficiais passados, em grande parte controlada pelas condições paleoclimáticas, acham-se registrados nos depósitos sedimentares dos últimos milênios (Turcq et al. 1998, Turcq et al. 2002b). A matéria orgânica, constituinte destes depósitos, conserva informações paleoambientais sobre sua origem, condições de formação, transporte e deposição. Estes dados podem ser obtidos através da análise de sua composição, que inclui uma variedade de indicadores isotópicos e moleculares (Meyers \& Ishiwatari 1993, Meyers 1994, 2003). Desta forma, a análise da matéria orgânica presente em sedimentos lacustres é considerada uma importante ferramenta para os estudos paleoambientais. De outra forma, a acumulação de carbono em sistemas lacustres deve ser mais bem entendida para uma melhor compreensão do ciclo do carbono em áreas continentais ao longo dos últimos milênios.
Globalmente, a biota terrestre é um sumidouro significativo de dióxido de carbono $\left(\mathrm{CO}_{2}\right)$ atmosférico. Estudos recentes do IPCC (Intergovernmental Panel on Climate Change) para a década de 1990 estimam a biota terrestre como sendo um sumidouro líquido de aproximadamente $1,4 \mathrm{GtC}$ de carbono por ano (assimilação líquida pela biota terrestre menos as emissões devidas às mudanças dos usos da terra). É provável que a maior parte deste suposto sumidouro ocorra nas florestas das latitudes médias e dos trópicos. Estudos do ciclo do carbono do Experimento LBA (Large scale atmosphere-Biosphere experiment in Amazonia) estão mostrando que as florestas não perturbadas da Amazônia comportam-se como uma armadilha para o carbono, com taxas na faixa de 1 a 7 toneladas por hectare por ano, ao passo que as áreas inundadas e os rios podem estar agindo como fonte de carbono de até 1,2 toneladas por hectare por ano (Nobre \& Nobre 2002). O desmatamento e a queima de biomassa representam uma emissão líquida de aproximadamente $0,2 \mathrm{GtC}$ de carbono por ano na Amazônia brasileira (Nobre \& Nobre 2002). Entretanto a sedimentação em áreas inundadas ainda é muito pouco estudada.

Os lagos ocupam cerca de $2 \times 10^{6} \mathrm{~km}^{2}$ (Adams \& Faure 1998) a $2,7 \times 10^{6} \mathrm{~km}^{2}$ (Einsele et al. 2001), ca. $0,8 \%$ da superfície do oceano ou $2 \%$ da superfície terrestre. Uma elevada quantidade de carbono atmosférico é soterrada no processo de sedimen- 
tação $(\sim 0,7 \mathrm{GtC} / \mathrm{ano})$ que atinge mais de um quarto da sedimentação anual de carbono atmosférico em oceanos modernos. Isto é conseguido principalmente com a rápida acumulação de sedimentos lacustres e um elevado fator de preservação (um fator médio cerca de 50 vezes mais elevado do que nos oceanos) (Einsele et al. 2001).

No entanto, o câmbio de $\mathrm{CO}_{2}$ entre o oceano e a atmosfera trouxe um aumento global do $\mathrm{CO}_{2}$ atmosférico durante o Holoceno (Einsele et al. 2001). A ocorrência de incêndios associados a períodos climáticos secos provavelmente foi um mecanismo que possibilitou a transferência de carbono de ecossistemas florestais para o sistema atmosférico.

Durante o último máximo glacial (a cerca de 18.000 anos atrás) ocorreu uma redução dos estoques de carbono em diversos tipos de vegetação e solos do mundo. Uma estimativa feita por Crowley (1995) avaliou uma remoção de 530 a $1160 \mathrm{GtC}$ de carbono do sistema terrestre durante este período (1995), o que acarretou num estoque global de $960 \mathrm{GtC}$ deste elemento. Com o retorno das condições mais quentes e úmidas, ocorreu um incremento de $140 \%$ nesta estocagem, chegando a atingir $2300 \mathrm{GtC}$. As florestas tropicais e floresta sazonal tropical (semi-decídua) apresentaram um aumento de 64,7 para 202 e 127,4 para $249 \mathrm{GtC}$ de carbono, respectivamente (Adams et al. 1990).

Van Campo et al. (1993) estimaram mudanças no estoque de carbono em $713 \mathrm{GtC}$ na mudança do período glacial para o interglacial. Estimativa de Crowley (1995) corroborou uma massiva mudança do estoque de carbono do último máximo glacial (UMG). Cerca de 530 a $1160 \mathrm{GtC}$ de carbono foram removidos do sistema terrestre durante o UMG. Uma nova estimativa de Adams \& Faure (1998) chegou a uma mudança de $1500 \mathrm{GtC}$ de carbono durante o UMG, com limites de erro entre 900 e $1900 \mathrm{GtC}$. Estes valores são superestimados em relação ao balanço de massa de carbono, calculados a partir de dados de $\delta^{13} \mathrm{C}$ e estoques de carbono em diversos compartimentos, que estima de 310 a $550 \mathrm{GtC}$ de carbono a mudança do UMG para o presente interglacial (Bird et al. 1994).

Para a Amazônia, no UMG, Behling (2001) considera uma redução de $40 \%$ na área de floresta e de $20 \%$ do estoque de carbono. Turcq et al. (2002a) ressaltando as incertezas desta estimativa, consideram uma redução entre 6 e 56\% do estoque de carbono para o mesmo período. Adams \& Faure (1998) estimaram as alterações do estoque de carbono das florestas tropicais durante o Holoceno. Entre o Holoceno Médio (8.000 a 5.000 anos cal AP) e o presente ocorreu uma diminuição de cerca de $115 \mathrm{GtC}$ de carbono nestes ecossistemas. Este período coincide com a intensificação de queimadas associadas a períodos mais secos, como observado por diversos estudos de sedimentação de partículas orgânicas carbonizadas na América do Sul (Cordeiro 1995, Cordeiro et al. 1997, 2008, Albuquerque 1998, Turcq et al. 1998, Simões Filho 2000, Elias et al. 2001). Estes dados também coincidem com o aumento nos níveis de $\mathrm{CO}_{2}$ atmosférico revelados pelo testemunho de gelo de Taylor Dome, Antártida (Indermühle et al. 1999). Assim como os estudos da deposição de partículas carbonizadas mostram os possíveis processos de transferência de carbono dos sistemas terrestres para o atmosférico em estudos paleoclimáticos, o estudo da acumulação de carbono nos sistemas lacustres mostram a incorporação diferencial de carbono nestes sistemas relacionados a mudanças climáticas regionais e globais.

As planícies de inundação, que na Amazônia são chamadas de várzeas, compreendem cerca de 5 a $8 \%$ da superfície da Bacia Amazônica e constituem importantes sítios de produção, estocagem (Moreira-Turcq et al. 2004) e exportação de carbono (Moreira-Turcq et al. 2008), proveniente tanto do Rio Amazonas quanto da produção in situ e da floresta de Terra firme. Portanto, trata-se de uma região com grande potencial para a utilização de diferentes indicadores paleoambientais, onde pouquíssimos estudos (Moreira-Turcq et al. 2004, Moreira 2008) desta natureza foram realizados até o momento (MoreiraTurcq et al. 2004, Moreira 2008). Estudos recentes têm demonstrado que a taxa anual de acumulação de carbono em lagos de várzea é da mesma ordem de grandeza da exportação anual em carbono orgânico de Rios para o oceano (Moreira-Turcq et al. 2004).

\section{OBJETIVOS}

Este trabalho tem como principal objetivo a descrição da sedimentação orgânica em diferentes sistemas de lagos da Amazônia, como os lagos sob influência direta da ação fluvial (lagos de várzea) e 
lagos isolados desta dinâmica. O conjunto dos dados obtidos neste estudo nos permitirá inferir sobre:

1) Os diferentes papéis destes ecossistemas na estocagem de carbono em diversas escalas temporais (centenas e milhares de anos) e sua importância sobre o processo de estocagem de carbono na Amazônia;

2) A utilização do estudo da deposição de carbono no que tange ao entendimento dos processos paleoambientais e antrópicos na Amazônia;

3) A integração de informações referentes ao estudo da acumulação de carbono nos diferentes sistemas estudados permitirá entender a estocagem de carbono nas vastas áreas de planícies de inundação em relação a mudanças paleoclimáticas regionais, determinado pelo comparativo dos estudos paleoclimáticos dentro e fora da dinâmica fluvial.

\section{SÍTIOS DE ESTUDO}

A localização das áreas de estudo estão indicadas na Figura 1 e a descrição das mesmas segue nos subitens abaixo.

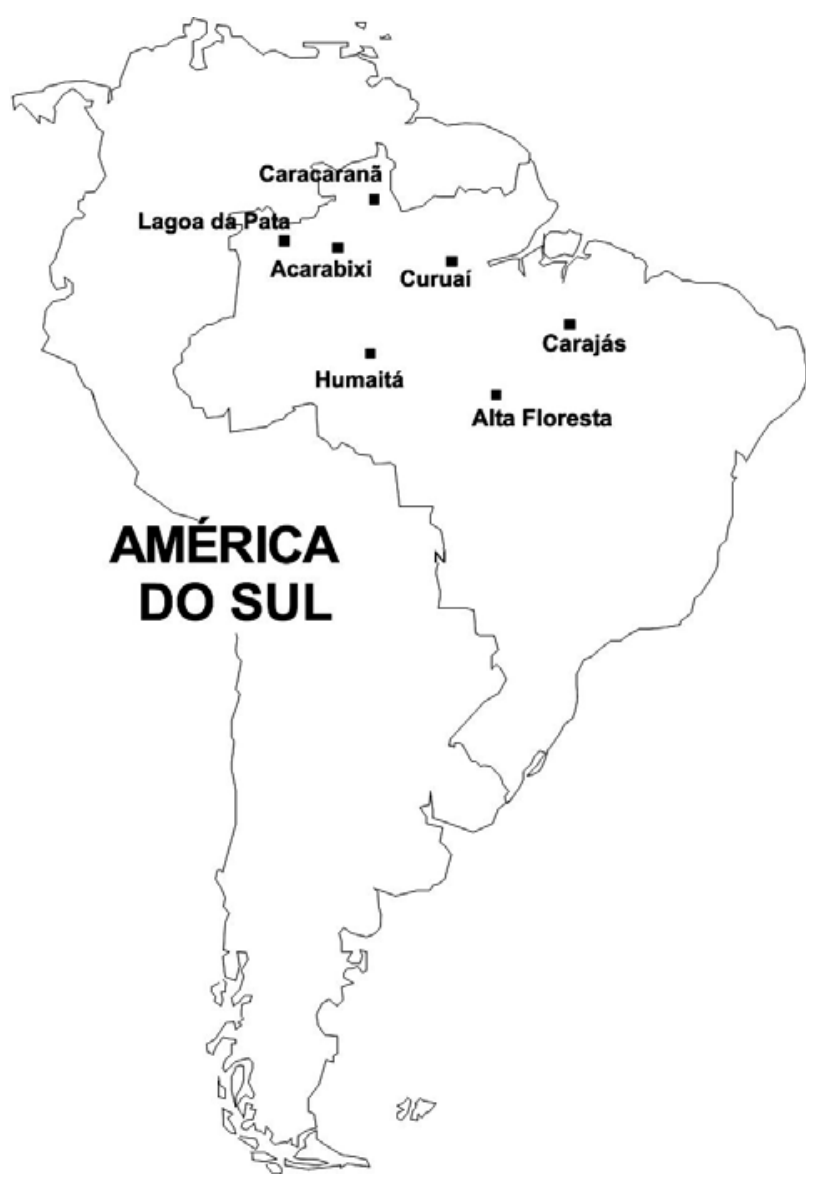

Figura 1. Localização aproximada das áreas de estudo. Figure 1. Approximate location of the study areas.
LAGOS INFLUENCIADOS PELA DINÂMICA FLUVIAL: LAGOS DE VÁRZEA: SANTA NINHA E ACA$R A B I X I$

Devido a uma topografia plana (que não chega a exceder os $100 \mathrm{~m}$ acima do nível do mar), solos pouco drenados, grande variação sazonal da precipitação e altos níveis de pluviosidade, extensas áreas da bacia Amazônica são permanente ou temporariamente inundadas. Estas regiões, conhecidas localmente como várzeas, ocupam uma área que varia entre 300.000 e $500.000 \mathrm{~km}^{2}$ (Martinez \& Le Toan 2007), o que representa $c a .5$ a $8 \%$ da superfície da bacia.

As várzeas são ambientes extremamente produtivos, onde o material orgânico e sedimentar, proveniente tanto do rio quanto da floresta de Terra firme, podem ficar estocados de forma temporária ou permanente. Existem estimativas sobre a quantidade de carbono armazenado nos solos e na vegetação amazônicos (Cerri et al. 2007, Tian et al. 2000, Adam \& Faure 1989). No entanto, o que está estocado nas várzeas desta região ainda vem sendo pouco explorado, com apenas alguns estudos realizados até o momento.

Alguns destes estudos observaram que, através do balanço de massa de sedimento (Dunne et al. 1998) e carbono (Moreira-Turcq et al. 2003) no Rio Amazonas, ocorria uma perda de material entre as cidades de Manaus e Óbidos. Estes dados revelam que os lagos de várzeas podem atuar como armadilha de sedimentos e de carbono (Moreira-Turcq et al. 2004).

Para o estudo da acumulação de carbono em ambientes inundáveis foram escolhidos dois lagos: o Lago Santa Ninha, situado na Várzea do Lago Grande de Curuai e o Lago Acarabixi. Para ambas as áreas de estudo foram analisadas dois testemunhos.

Lago Santa Ninha, Várzea do Lago Grande de Curuai

A área ocupada pela várzea do Lago Grande de Curuai varia entre 1.340 e $2.000 \mathrm{~km}^{2}$ (Martinez \& Le Toan 2007), de acordo com o período de cheia e vazante, podendo alcançar até $3600 \mathrm{~km}^{2} \mathrm{em}$ períodos de cheia extrema. Sua localização está entre as latitudes sul $01^{\circ} 50^{\prime} \mathrm{S}-02^{\circ} 15^{\prime} \mathrm{S}$ e longitude oeste $55^{\circ} 00^{\prime} \mathrm{W}-$ $56^{\circ} 05^{\prime} \mathrm{W}$, na margem sul do Rio Amazonas, a $850 \mathrm{~km}$ da sua desembocadura no oceano Atlântico. 
Esta várzea está permanentemente conectada ao Rio, sendo composta por diversos lagos de águas pretas, como o Curumucuri e Açaí, e de águas brancas, como o Lago Grande, Poção, Salé e o lago Santa Ninha, analisado neste trabalho.

\section{Várzea do Acarabixí}

O lago Acarabixi, se encontra na região do médio Rio Negro, $\left(00^{\circ} 20^{\prime} \mathrm{S} ; 64^{\circ} 29^{\prime} \mathrm{O}\right)$, numa área de planície fluvial na margem esquerda do Rio Negro (AM), próximo a campos de dunas fósseis. Por sofrer constante influência das águas do rio Negro, o Lago Acarabixi possui águas com baixo $\mathrm{pH}$, próximo a 4,2. $\mathrm{O}$ clima na região pertence ao grupo A (clima Tropical Chuvoso) do sistema de classificação de KÖPPEN. Caracteriza-se por apresentar temperatura média do mês mais frio sempre superior a $18^{\circ} \mathrm{C}$. O tipo climático da região é Af, que corresponde ao clima de florestas tropicais (constantemente úmido). Tanto a temperatura quanto a precipitação sofrem um mínimo de variação anual e mantêm-se em um nível elevado. As temperaturas da região norte são geralmente elevadas, sendo as médias da Amazônia em torno de $24^{\circ} \mathrm{C}$ a $26^{\circ} \mathrm{C}$, com variação anual pouco significativa. Porém, as variações diárias de temperatura oscilam entre $8^{\circ} \mathrm{C}$ e $14^{\circ} \mathrm{C}$. A vegetação presente na planície fluvial em Acarabixi é caracterizada por floresta inundada.

\section{LAGOS ISOLADOS DA DINÂMICA FLUVIAL}

Morro dos Seis Lagos. Região do Alto Rio Negro (AM)

A região do Alto Rio Negro, onde se encontra localizado o Morro dos Seis Lagos, caracteriza-se por uma superfície peneplanizada estimada de $75 \mathrm{~m}$. A estrutura denominada Morro dos Seis Lagos é formado por uma canga laterítica e possui uma superfície com diversas depressões por colapso. Sua altitude máxima está em torno de $360 \mathrm{~m}$.

Os lagos ocupam depressões fechadas e são favorecidos pela impermeabilidade do substrato e abastecimentos de mananciais vizinhos. A variação do nível superficial oscila em função direta das precipitações, apesar de estarem sempre sendo alimentados por outros fluxos d'água, sugerem um sistema de percolação no interior da canga, através de suas cavernas e fraturas. A variação do nível hídrico é bastante pronunciada entre a estação chuvosa e a seca. Segundo informação local e observações pessoais foi notada que a Lagoa da Pata sofre também oscilações importantes no seu nível hídrico em função das variações sazonais e inter-anuias das precipitações pluviométricas.

A vegetação na região peneplanizada que circunda o morro é constituída por Floresta Ombrófila Densa latifoliada (Floresta Pluvial Tropical) que se desenvolve sobre solos extremamente pobres em nutrientes. A exuberância das matas é mantida pelas condições climáticas locais (quente e úmido) que permite uma rápida ciclagem de nutrientes nas primeiras camadas do solo florestal. Estas condições permitem o desenvolvimento de fisionomia florestal nas regiões da superfície aplainada do Morro dos Seis Lagos.

Da base até o topo do Morro ocorre uma transição de Floresta Ombrófila Densa, para uma vegetação do tipo aberta limitada pela ausência de solo bem formado. Esta vegetação apresenta características xerofíticas com grande abundância de gramíneas, bromeliáceas, orquidáceas. Os extratos vegetacionais desenvolvem-se em um emaranhado de raízes superficiais, sobre a canga hematítica. No topo da elevação em áreas depressivas onde se acumula matéria orgânica proveniente da produção da própria vegetação desenvolvem-se comunidades vegetais com extrato arbóreo de até $20 \mathrm{~m}$ de altura.

O clima na região é quente e úmido, sem estação seca definida (equatorial), do tipo Af (classificação de Köppen). Com um total de precipitação anual em torno de $2900 \mathrm{~mm}$, a região apresenta uma diminuição das precipitações, a partir de Julho até o mês de Novembro. O mês menos chuvoso é o de Setembro, em torno de $150 \mathrm{~mm}$. Este período é chamado regionalmente de verão, quando as precipitações são mais baixas e a insolação é maior.

A Lagoa da Pata apresenta-se, com uma superfície aproximada de $150.000 \mathrm{~m}^{2}$ e subdivida em quatro alvéolos de dissolução. Os principais pigmentos (clorofila $a, b, c$, carotenóides e feopigmentos) foram analisados, por colorimetria, na coluna d'água. Os resultados mostram que a Lagoa apresenta concentrações moderadas de clorofila- $a\left(1,56 \mathrm{mg} / \mathrm{m}^{3}\right)$ e de clorofila- $b$ $\left(1,09 \mathrm{mg} / \mathrm{m}^{3}\right)$. As concentrações de clorofila- $c$ foram relativamente altas $\left(3,01 \mathrm{mg} / \mathrm{m}^{3}\right)$. Os carotenóides foram da ordem de $2,08 \mathrm{mg} / \mathrm{m}^{3}$. As concentrações de feopigmentos (clorofila degradada) foram muito baixas.

Os principais parâmetros químicos e físico-químicos da água da Lagoa da Pata mostraram que sua compo- 
sição é muito semelhante aos determinados na água da chuva da região. Este fato é um indicativo da pouca entrada de nutrientes via escoamento superficial da bacia de drenagem da Lagoa da Pata. A produtividade primária do lago é provavelmente mantida pela ciclagem interna de nutrientes. $\mathrm{O}$ testemunho LPT V foi coletado na lagoa da Pata em 0¹7'09’'N e 660'36”W.

\section{A região da Serra dos Carajás}

A região de Carajás (P.A.) apresenta características de relevo pouco acentuado e localiza-se entre $5^{\circ} 50$ $6^{\circ} 35^{\prime}$ de latitude Sul e $49^{\circ} 30^{\prime}-52^{\circ} 00^{\prime}$ de longitude Oeste. Sob ponto de vista geomorfológico, Ab'Saber (1986) descreve a Serra de Carajás como um pequeno maciço xistoso mineralizado, que se salienta acima do nível geral das colinas cristalinas florestadas da acidentada área de divisão das águas entre os vales do Rio Xingu e Araguaia. A serra dos Carajás stricto sensu, possui $160 \mathrm{~km}$ de eixo maior, no sentido de leste para oeste, e $60 \mathrm{~km}$ de largura, de norte para o sul. A região de Carajás apresenta um clima do tipo tropical, quente e úmido enquadrando-se na classificação de Köpen como tipo "Aw”. Entretanto, apesar das altas precipitações anuais, Carajás situa-se em área da Amazônia sujeita a condições climáticas relativamente secas se comparadas a outras regiões, com pluviosidade média anual de $2116 \mathrm{~mm}$ (Silva et al. 1996) e com temperaturas médias anuais de $23^{\prime} 5^{\circ} \mathrm{C}$ $(835 \mathrm{~m})$ e $26^{\prime} 2^{\circ} \mathrm{C}(203 \mathrm{~m})$. O clima é do tipo Awi de Köppen, ou seja, tipo tropical úmido com estação chuvosa no verão e apresentando uma marcada seca de inverno com quatro meses de estiagem (IBGE 1977, Falesi 1986). O testemunho sedimentar (CSN 93/3) foi coletado em um lago de aproximadamente 12ha situado em depressão do platô laterítico da Serra Norte de Carajás na localidade denominada N4 a cerca de $800 \mathrm{~m}$ de altitude em $6^{\circ} 06^{\prime} 45^{\prime} \mathrm{S} 50^{\circ} 11^{\prime} 18^{\prime \prime} \mathrm{O}$.

\section{Humaitá (AM)}

A região de Humaitá, no Sul do Estado do Amazonas caracteriza-se por um relevo extremamente plano com ausência de Cuestas, Cristas, Tabuleiros ou Inselbergs e situa-se numa faixa de transição em área aplainada propícias á formação de lagos e charcos sazonais, abrangendo as coordenadas geográficas: $8^{\circ} 10^{\prime \prime} 00^{\prime} \mathrm{S}, 63^{\circ} 47^{\prime \prime} 48^{\prime} \mathrm{O}$; e $8^{\circ} 10^{\prime \prime} 00^{\prime} \mathrm{S}$; 6346"56’O. Tais áreas estão presentes em toda a região e formam um sistema de vários campos inundados circundados por vegetação de floresta e savana ocupando uma área estimada em $600 \mathrm{~km}^{2}$ (Pessenda et al. 1998). O clima é do tipo quente úmido, segundo o sistema de classificação de Köppen como sendo do tipo Afi - com duas estações definidas: período de estação seca com pouca ou nenhuma precipitação (abril a setembro), e período de estação chuvosa elevada. Apresenta precipitação anual de aproximadamente $2.500 \mathrm{~mm}$ anuais (outubro a março), com temperatura média anual de $26^{\circ} \mathrm{C}$ com mínima em torno de $18^{\circ} \mathrm{C}$ e temperatura máxima em torno de $36^{\circ} \mathrm{C}$ (Ab'Sáber 1979). Nesta região foram demonstradas mudanças na dinâmica da vegetação ao longo do Holoceno determinado por estudo isotópico da matéria orgânica do solo (Pessenda et al. 1998). A região de estudo é caracterizada por uma forte tendência de transição da floresta tropical ombrófila densa pela vegetação do tipo campo-cerrado. Nos últimos anos, os ecossistemas naturais da região vem sendo substituídos por áreas destinadas ás pastagens e ao cultivo da soja, fazendo parte de uma das áreas de maior pressão pela expansão da fronteira agrícola denominado "Arco do Desmatamento" da Amazônia que vai do Estado do Acre, passando pelo Estado de Rondônia em direção ao Sul do Estado do Pará e Norte do Estado do Mato-Grosso. Com o avanço da fronteira agroindustrial liderada pelo plantio da soja e da pecuária ao longo das últimas quatro décadas, poderão ser apagados determinados registros de ecossistemas passados, gerando lacunas face à compreensão de todo o passado biótico e climático do “cerrado" amazônico (Carvalho 2006).

No presente trabalho foi analisado o testemunho HUM 97/5 - 85cm (fatiado em seções amostrais de $2 \mathrm{~cm}$ ); o que permitirá identificar os processos climáticos e os eventos de queima que promoveram alterações na dinâmica da vegetação nesta área.

Lago Caracaranã - Região dos Lavrados (Savanas) de Roraima (RR)

A área de contato está situada em zona de tensão ecológica, onde as florestas tropicais úmidas mudam de forma abrupta para vegetação aberta - conhecida na região como lavrado. Estas savanas cobrem extensas porções ao Nordeste do Estado de Roraima. O limite floresta-savana está localizado a entre $2^{\circ}$ a $5^{\circ}$ Lat. N e $59^{\circ}$ a $62^{\circ}$ Long. O, onde se encontra um mosaico de formações vegetais, com enclaves de savanas em áreas de florestas e vice-versa (Sanaiotti 1997). O clima 
atual é úmido e marcado por estação seca prolongada de até 6 meses. A região encontra-se inserida entre dois centros de alta precipitação, a saber: As Guianas que recebem diretamente a umidade atlântica trazida pelos ventos alísios de leste e nordeste e a Amazônia Central, onde se encontra o máximo da zona de convergência intertropical (ZCIT). Considerando-se um nível mais amplo, os campos de Roraima estão situados em um corredor seco de orientação SE-NE, que corta a planície amazônica entre o sul do Estado do Pará e a região centro-leste do Estado de Roraima. A região estudada é a mais seca deste corredor, mostrando um gradiente de precipitação anual de nordeste para sudoeste, saindo das formações de savana (1100-1400mm/ano), atravessando uma larga faixa de transição savana-floresta estacional (1700$2000 \mathrm{~mm} / \mathrm{ano}$ ) e alcançando as florestas úmidas (2000$2300 \mathrm{~mm} / \mathrm{ano}$ ) no sul do estado (Barbosa 1997).

\section{Região de Alta Floresta (MT)}

A cidade de Alta Floresta $\left(09^{\circ} 52^{\prime} \mathrm{S} ; 6^{\circ} 06^{\prime}, 288 \mathrm{~m}\right)$ localiza-se ao Norte do estado de Mato em área de intensa mudança do uso da terra. $\mathrm{O}$ processo de ocupação iniciou-se no começo da década de setenta, através do projeto de colonização da Empresa Integração Desenvolvimento e Colonização (INDECO S.A.). Alta Floresta fica situada em região de relevo relativamente plano em área do Planalto cristalino brasileiro com clima do tipo Am (classificação de Köppen), úmido com três meses de estação seca. A região apresenta uma estação seca muito intensa, de Junho a Agosto. Neste período, derruba-se a mata onde a partir de agosto inicia-se o processo de queima da biomassa. A região apresenta ocorrência de Floresta Ombrófila Densa e sofreu a partir da década de setenta um intenso processo de ocupação com vastas áreas florestais, alvos de processos de queima de biomassa florestal para fins agropecuários.

O sistema límnico objeto do presente estudo foi formado a partir do barramento do escoamento d'água ocasionado pela construção da rodovia $\mathrm{Br} 152$ no ano de 1978. A barragem fica situada $9^{\circ} 58^{\prime} \mathrm{S}$ e $55^{\circ} 49^{\prime} \mathrm{O}$ às margens da citada rodovia.

\section{MATERIAL E MÉTODOS}

Testemunhos curtos, que traduzem períodos mais recentes, ou seja, últimas centenas de anos, e longos que representam os últimos milhares de anos foram coletados respectivamente na Várzea do Lago Grande de Curuai e na Várzea do Acarabixi. Para a coleta dos testemunhos longos nos dois sistemas de Várzea foi utilizado o sistema de vibro-testemunhagem desenvolvido por Martin et al. (1995). Já os testemunhos curtos foram retirados manualmente. Os testemunhos da Lagoa da Pata (AM) foram coletados, utilizando "piston core" acoplado a um percursor desenvolvido por Antônio Rommanazi (GEOLEMN, Departamento de Geoquímica, UFF). Uma balsa super-leve permitiu o transporte em selva tendo sido desenvolvida especificamente para a expedição. Os testemunhos dos lagos de Carajás e de Alta Floresta foram coletados manualmente inserindo-se o tubo de alumínio no sedimento e tampando-se, logo após, sua extremidade livre e sacando o testemunho do sedimento. Todos os testemunhos foram coletados com tubos de alumínio de $7,5 \mathrm{~cm}$ de diâmetro. Os testemunhos coletados foram descritos e então secionados em seções de $1 \mathrm{~cm}$ dependendo dos contatos litológicos, para obtenção de uma alta resolução temporal. Antes da abertura, os testemunhos foram radiografados para a análise das estruturas sedimentares, que auxiliam na abertura e no fatiamento do mesmo. Os testemunhos foram abertos em seção transversal com auxílio de uma serra circular e em seguida foram fatiados em seções para analises dos parâmetros estudados.

Logo após a abertura dos testemunhos, cada amostra foi pesada ainda úmida para posterior secagem em estufa a $40^{\circ} \mathrm{C}$. O teor em água e a densidade aparente foram determinados, para cada seção, através da diferença entre o peso úmido e o peso seco.

A geocronologia dos testemunhos curtos foi realizada através do ${ }^{210} \mathrm{~Pb}$ e a taxa de sedimentação foi calculada pelo método C.E.C.S. (constante fluxo e constante sedimentação). Para a cronologia dos registros milenares (testemunhos longos) foram realizadas datação com carbono $14\left({ }^{14} \mathrm{C}\right)$. Estas amostras foram secas em estufa à $50^{\circ} \mathrm{C} / 48$ horas, e analisadas pela técnica de Espectrometria de Massa com Aceleradores (Accelerator Mass Spectrometry - AMS). As idades foram devidamente calibradas, com o auxílio do programa Calib 5.0.2 (disponível na internet, no site http://radiocarbon.pa.qub.ac.uk/ calib/), passando a serem expressas em anos cal AP (antes do presente). Com exceção, as idades do registro da Pata foram expressos em idades 14C 
por algumas das idades estarem acima da faixa que permitem a realização de calibração.

As determinações de carbono orgânico e nitrogênio total, ${ }^{13} \mathrm{C} \mathrm{e}{ }^{15} \mathrm{~N}$ das amostras totais de sedimento foram obtidos em espectrômetro de massa acoplado a um analisador automático de Carbono e Nitrogênio nos seguintes laboratórios.

a) Lagos de Várzea, Lago Grande de Curuai e Acarabixi - do UC Davies Stable Isotope Facility - Departamento de Agronomia da Universidade da Califórnia).

b) Lagoa da Pata - Environmental Isotope Laboratory (Universidade de Waterloo, Canadá).

c) Caracaranã, Carajás e Alta Floresta - Programa de Geoquímica da Universidade Federal Fluminense em analisador automático CHN Perkin Elmer.

A taxa de acumulação de carbono (TAC) foi calculada através da seguinte fórmula:

TAC $\left(\mathrm{g} / \mathrm{cm}^{2} / \mathrm{ano}\right)=$ concentração em carbono $(\mathrm{g} / \mathrm{g})$ $\times$ densidade aparente $\left(\mathrm{g} / \mathrm{cm}^{3}\right) \times$ taxa de sedimentação (cm/ano)

Para os registros de Carajás, Caracaranã e Alta Floresta foram quantificadas as partículas de carvões. As amostras das seções sedimentares foram diluídas em água destilada numa proporção de $0,1 \%$ de sedimento seco em água destilada. A solução foi homogeneizada num becker mantendo-se o material em suspensão, quando foram retiradas alíquotas de $1 \mathrm{ml}$ com micropipeta. Após, as alíquotas foram filtradas em filtros de acetato de celulose $24 \mathrm{~mm}$ previamente pesados, que foram colados em laminas acrílicas com acetato de etila.

Para determinação do carbono grafítico foi usado o método descrito por Lim \& Cachier (1996). Este método tem como princípio o isolamento do carbono grafítico através de sucessivos ataques. As etapas consecutivas eliminam ácidos húmicos, carbonatos, silicatos e a matéria orgânica lábil. O método empregado apresenta as seguintes fases: - Ataque alcalino $(\mathrm{NaOH}, 5 \%)$, - Ataque ácido para eliminação de carbonatos (HCL) e silicatos (HCL/HF), - eliminação de fluorsilicatos (HCL) - Oxidação da Humina $\left(\mathrm{H}_{2} \mathrm{SO}_{4} / \mathrm{Cr}_{2} \mathrm{O}_{7}\right)$. O Carbono Orgânico Total (COT) do sedimento total e dos resíduos contendo carbono grafítico foram determinados em analisador automático de carbono e nitrogênio.
Para o registro de Carajás foi determinada a concentração de derivados de clorofila no perfil sedimentar através de metodologia baseada no método descrito por Swain et al. (1985). Foi realizada extração com $15 \mathrm{ml}$ de acetona $90 \%$ agitando-se e centrifugando por pelo menos três vezes consecutivas. $\mathrm{O}$ extrato contendo pigmentos derivados de clorofila foi então avolumado a $50 \mathrm{ml}$ e lido em espectrometria ótica (Perkin Elmer) com varredura entre 500 a $800 \mathrm{~nm}$. As concentrações de derivados de clorofila foram expressas como: Unidade de Derivados de Pigmentos Sedimentares (UDPS). Uma UDPS é igual a uma absorbância de 1,0 em uma célula de $10 \mathrm{~cm}$ em $100 \mathrm{ml}$ de solvente em 1,0g de matéria orgânica (Sanger \& Gorham 1972).

No registro de Caracaranã foram determinadas as concentrações de elementos minerais por espetrometria de infravermello com transformada de Fourier. As análises mineralógicas foram realizadas na fração total do sedimento e permitirá determinar a proporção dos diferentes constituintes minerais por espectrometria de infravermelho com transformada de Fourier (espectrofotômetro de infravermelho Perkin Elmer, SPECTRUM 1000). Esta técnica é baseada na proporcionalidade entre a absorbância e a concentração das espécies na amostra (Frolich et al. 1989, Bertaux et al. 1998).

No registro de Alta Floresta foi determinado o mercúrio total. Um grama de cada amostra foi digerida usando $20.0 \mathrm{ml}$ "água régia" diluída a $50 \%$ num sistema fechado. A concentração de mercúrio foi medida nos extratos sedimentares através de absorção atômica de vapor a frio (Espectrofotômetro Bacharach, Coleman ${ }^{\circledR}$ Model 50 D). Simultaneamente, o mesmo procedimento foi utilizado com padrão sedimentar (Buffalo River standard sediment, National Institute of Standards and Technology-NIST-Catalog

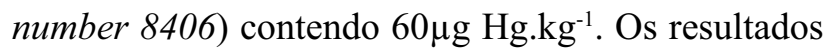
da analise do padrão mostraram concentrações de 58 $\pm 5 \mu \mathrm{g} \cdot \mathrm{Hg} \cdot \mathrm{kg}^{-1}(\mathrm{~N}=15)$.

\section{RESULTADOS}

LAGOS DENTRO DA DINÂMICA FLUVIAL AMAZONNICA: LAGOS DE VÁRZEA.

As várzeas amazônicas são consideradas um dos ecossistemas mais produtivos do mundo. A produção 
orgânica estimada para os sistemas de várzea amazônicos é de $8,4 \times 10^{6}$ Ton C/ano (Junk 1997) onde as macrófitas contribuem com cerca de $5 \times 10^{6} \mathrm{Ton} \mathrm{C} / \mathrm{ano}$; as árvores e gramíneas com $2,4 \times 10^{6} \mathrm{Ton} \mathrm{C} /$ ano e o plâncton com 1 x 106 Ton C/ano. A produção orgânica nos diferentes sistemas de várzeas está relacionada, principalmente, ao tipo de água destes lagos (brancas, pretas ou claras) e estas são diretamente dependentes dos rios que os drenam. Por outro lado, os lagos de várzeas, apesar de poucos estudos terem sido realizados até esta data (Devol et al. 1984, Smith-Morril 1987, Moreira-Turcq et al. 2004), podem ser caracterizados por apresentarem taxas de sedimentação relativamente altas, quando comparados aos outros lagos da região Amazônica. Ao mesmo tempo, estas taxas de sedimentação são variáveis ao longo da Bacia e mesmo no interior de um mesmo sistema de lagos. Estas variações parecem estar diretamente relacionadas ao tipo de conexão que os lagos possuem com o curso principal (temporária ou permanente), a proximidade (comprimento do canal de conexão) ao curso principal (lagos próximos ao Rio tem tendência a serem mais influenciados pelas características físicoquímicas do mesmo), e finalmente pela geometria dos canais de conexão (mais ou menos meandrosos).

\section{Várzea do Lago Grande de Curuai}

\section{Testemunho curto: sedimentação atual}

Os resultados obtidos no testemunho (TA11) curto $(1,10 \mathrm{~m})$ coletado no Lago Santa Ninha mostram que a taxa de sedimentação é alta e variável (entre $0,56 \mathrm{~cm} /$ ano e $1,35 \mathrm{~cm} / \mathrm{ano}$ ) ao longo dos últimos cem anos (Figura 2). Esta variação está diretamente relacionada à granulometria dos grãos. Na parte mais superficial do testemunho a granulometria apresenta-se mais grossa (em média $50 \%$ de areia, $25 \%$ de silte e $25 \%$ de argila) e é caracterizada por uma taxa de sedimentação inferior; já no meio do testemunho a areia desaparece e o silte aumenta, e a taxa de sedimentação alcança o máximo. Já na porção mais basal do testemunho, a areia retorna e a taxa volta a diminuir. Esta litologia extremamente diferenciada representa uma excelente oportunidade para o estudo da sedimentação orgânica neste ambiente. Altas taxas de sedimentação são típicas de lagos de várzea que margeiam grandes rios (Goodbred \& Kuehl 1998). Os teores de carbono no testemunho TA11 (Figura 2) são relativamente homogêneos $(\sim 1 \%)$ com alguns picos
( $2 \%$ de C) presentes nas frações mais grossas relativos à presença de detritos e restos vegetais. Estes teores de carbono são na mesma faixa dos teores encontrados nos sedimentos do Rio Amazonas (Hedges et al. 1986, Moreira-Turcq et al. 2003) atestando que os sedimentos depositados no Lago Santos Ninha têm sua principal origem nos sedimentos transportados pelo Rio. A razão $\mathrm{C} / \mathrm{N}$ que fornece informações sobre a origem e o tipo da matéria orgânica também corrobora com esta hipótese. O TA11 apresenta um C/N médio de 9 que é extremamente próximo do encontrado no Amazonas. Este $\mathrm{C} / \mathrm{N}$ indica uma matéria orgânica originária principalmente devido à drenagem dos solos que margeiam o Rio.

Apesar dos teores relativamente baixos (cerca de $1 \%$ ) em carbono a taxa de acumulação deste no testemunho TA11 é elevada (Figura 2) apresentando um fluxo médio de carbono de $100 \mathrm{~g} \mathrm{C} / \mathrm{m}^{2} /$ ano. O fluxo de carbono variou ao longo do testemunho entre 30 e $250 \mathrm{~g} \mathrm{C} / \mathrm{m}^{2} / \mathrm{ano}$, sendo que a litologia parece ser o fator determinante na armadilha de carbono deste sistema. Outros estudos realizados em lagos de várzea da região Amazônica também observaram altas taxas de acumulação de carbono como é o caso Devol et al. (1984) que determinou uma taxa de $44 \mathrm{gC} / \mathrm{m}^{2} /$ ano para o Lago Jacaretinga e de $28 \mathrm{gC} / \mathrm{m}^{2} /$ ano para o Lago Cristalino, ambos localizados as margens do Rio Solimões. Em ambos os lagos os testemunhos foram de apenas alguns centímetros e datados com ${ }^{210} \mathrm{~Pb}$. Na mesma linha de pesquisa Smith-Morril (1987) estimou uma deposição de carbono variando entre 31 e $137 \mathrm{gC} / \mathrm{m}^{2} /$ ano em diferentes testemunhos do Lago Calado, no Rio Solimões. Todos estes valores estão na mesma ordem de grandeza dos valores encontrados neste trabalho o que fortalece a hipótese de que os lagos de várzea desempenham um papel fundamental na atualmente na retenção de carbono dentro da Amazônia.

\section{Testemunho longo: sedimentação milenar}

A análise do testemunho TA14, também coletado no lago Santa Ninha e apresentando $2,70 \mathrm{~m}$, revela que a dinâmica sedimentar desta região sofreu algumas modificações ao longo dos últimos 5700 anos cal. A.P.. O período entre 5000 e 5700 anos cal A.P, que corresponde a parte mais basal do testemunho, registrou os valores mais elevados de carbono orgânico de todo o perfil (até $8 \%$ de carbono), acompanhados por 

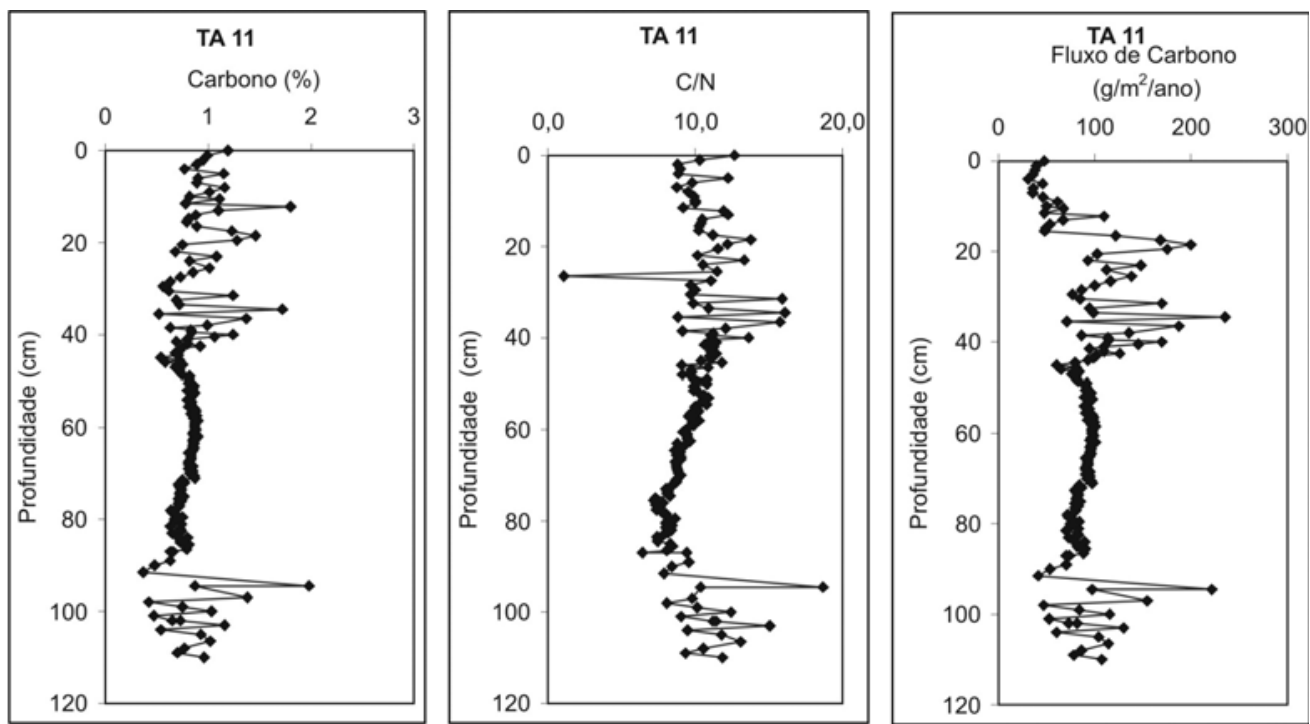

Figura 2. Concentração de carbono, relação $\mathrm{C} / \mathrm{N}$ e fluxo de carbono do testemunho curto TA11, coletado no lago Santa Ninha, Várzea de Curuai. Figure 2. Carbon concentration, C/N ratio and carbon flow in the short core TAl1 colected at lake Santa Ninha, Várzea de Curuai.

taxas de acumulação de carbono superiores a $400 \mathrm{~g}$ $\mathrm{C} / \mathrm{m}^{2} /$ ano (Figura 3) e por uma alta taxa de sedimentação (com valores por volta de $0,35 \mathrm{~cm} / \mathrm{ano}$ ). A relação $\mathrm{C} / \mathrm{N}$ encontrada durante esta fase apresentou uma média de 20, indicando a presença de matéria orgânica de origem de plantas vasculares. Estes dados refletem um ambiente úmido, com elevado aporte de matéria orgânica, mais acentuado do que o observado no testemunho anterior.

Porém, a partir deste período até os últimos 100 anos, observou-se uma queda nestes valores, onde a concentração de carbono revelou-se extremamente baixa (chegando a atingir o valor mínimo de $0,1 \%$ ), assim como a relação $\mathrm{C} / \mathrm{N}$ e o fluxo de carbono, que durante um longo período apresentou média de 2,5g/ $\mathrm{m}^{2} /$ ano.

Estas alterações na dinâmica sedimentar foram acompanhadas por mudanças no tipo de vegetação, como evidenciado pela analise da relação $\mathrm{C} / \mathrm{N}$. Desta forma pode-se sugerir que as variações ocorridas no fluxo de carbono acompanham as alterações dos ambientes sedimentares.

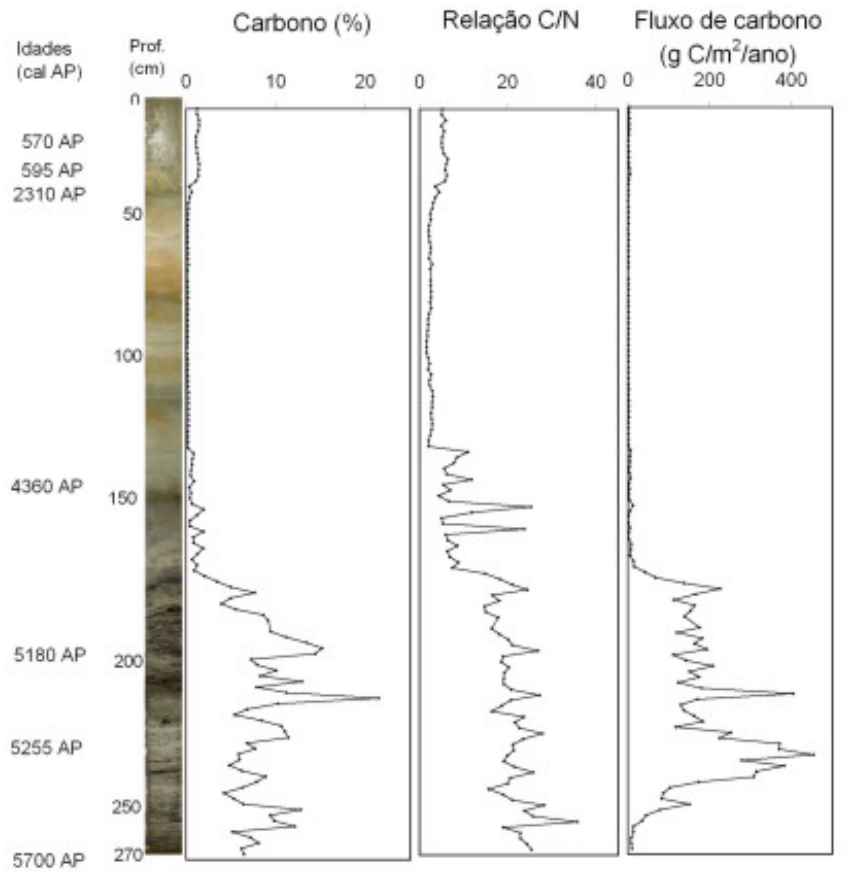

Figura 3. Concentração de carbono, relação $\mathrm{C} / \mathrm{N}$ e fluxo de carbono do testemunho longo TA14, coletado no lago Santa Ninha, Várzea de Curuai. Figure 3. Carbon concentration, C/N ratio and carbon flow in the long core TA14 colected at lake Santa Ninha, Várzea de Curuai 


\section{Lago Acarabixi}

\section{Testemunho curto: sedimentação atual}

O testemunho (ACA 024) curto $(0,30 \mathrm{~m})$ coletado no Lago Acarabixi, Alto Rio Negro, apresentou uma taxa de sedimentação de $0,41 \mathrm{~cm} /$ ano. Esta alta taxa de sedimentação é comparável às taxas acima citadas encontradas em outros trabalhos (Devol et al. 1984, Smith-Morril 1987) realizados em lagos de várzea do Rio Solimões. E está na mesma faixa das taxas encontradas para os primeiros centímetros do testemunho TA11 e na parte mais basal do testemunho TA14, ambos do lago Santa Ninha. Os sedimentos do Lago Acarabixi, quando comparados com os do lago analisado anteriormente, são extremamente ricos em matéria orgânica, apresentando um teor médio ao longo dos $30 \mathrm{~cm}$ de $25 \%$ de carbono (Figura 4) contrariamente ao teor encontrado para o testemunho curto (TA11) e para a parte superior do testemunho TA14, da Várzea de Curuai. Este fato está principalmente relacionado ao fato de que o Rio Negro é caracterizado por teores elevados de matéria orgânica ( 10-20\%) em suas águas enquanto que o Rio Amazonas apresenta teores reduzidos de MO ( $2 \%)$. Estes dois parâmetros, juntamente com a litologia e a densidade aparente dos sedimentos, vão ser determinantes para a taxa de acumulação de carbono destes sistemas. A razão $\mathrm{C} / \mathrm{N}$ do ACA 024 apresentou um valor médio de 25 , o que indica uma matéria orgânica de origem terrestre (material vascular) muito diferente do material encontrado no TA11, também diretamente relacionado com o material carreado pelo Rio proveniente das vastas áreas peneplanizadas cobertas por vegetação de floresta tropical densa que se desenvolvem em solos arenosos.
O Lago Acarabixi apresentou uma taxa de acumulação média de carbono de $265 \mathrm{gC} / \mathrm{m}^{2} /$ ano (Figura 4). Esta taxa é um pouco menor na superfície (até os primeiros $5 \mathrm{~cm}$ ) e depois é relativamente constante e mais alta até $26 \mathrm{~cm}$, reduzindo novamente até o final. Isto indica claramente que o Lago Acarabixi nos últimos anos representa um local de estocagem para a matéria orgânica, porém apresentando flutuações, assim como o observado no lago Santa Ninha.

\section{Testemunho longo: sedimentação milenar}

Foram calculadas as taxas médias de acúmulo de carbono considerando uma perda na parte superior do registro de pelo menos 650 anos AP. Esta perda é compensada pela estimativa de taxa de acumulo de carbono realizada em testemunho curto no mesmo ponto de coleta descrito na seção anterior.

No primeiro período de sedimentação entre 10600 a 8200 anos cal. A.P. a taxa de acúmulo entre 10620 anos cal. A.P. a 10580 anos cal. A.P. apresentou um fluxo médio de $25,4 \mathrm{~g} / \mathrm{m}^{2} /$ ano provavelmente caracterizado por um período de relativa estabilidade hidrológica observado por uma deposição de matéria orgânica autóctone com altos valores de $\delta^{13} \mathrm{C}$ e baixos valores de $\mathrm{C} / \mathrm{N}$. Após um considerável aumento num curto intervalo de tempo entre aproximadamente 10580 a 10550 anos cal. A.P. é observado chegando a um fluxo médio de $493 \mathrm{~g} / \mathrm{m}^{2} /$ ano com valor máximo de $820 \mathrm{~g} / \mathrm{m}^{2} /$ ano em 10560 anos cal. A.P.. Este período marca evento extremo de alta taxa de sedimentação $(\sim 1,95 \mathrm{~cm} / \mathrm{ano})$ provavelmente tendo trazido material estocado em solos após a estabilidade hídrica da fase precedente. Após este evento extremo de acumulação
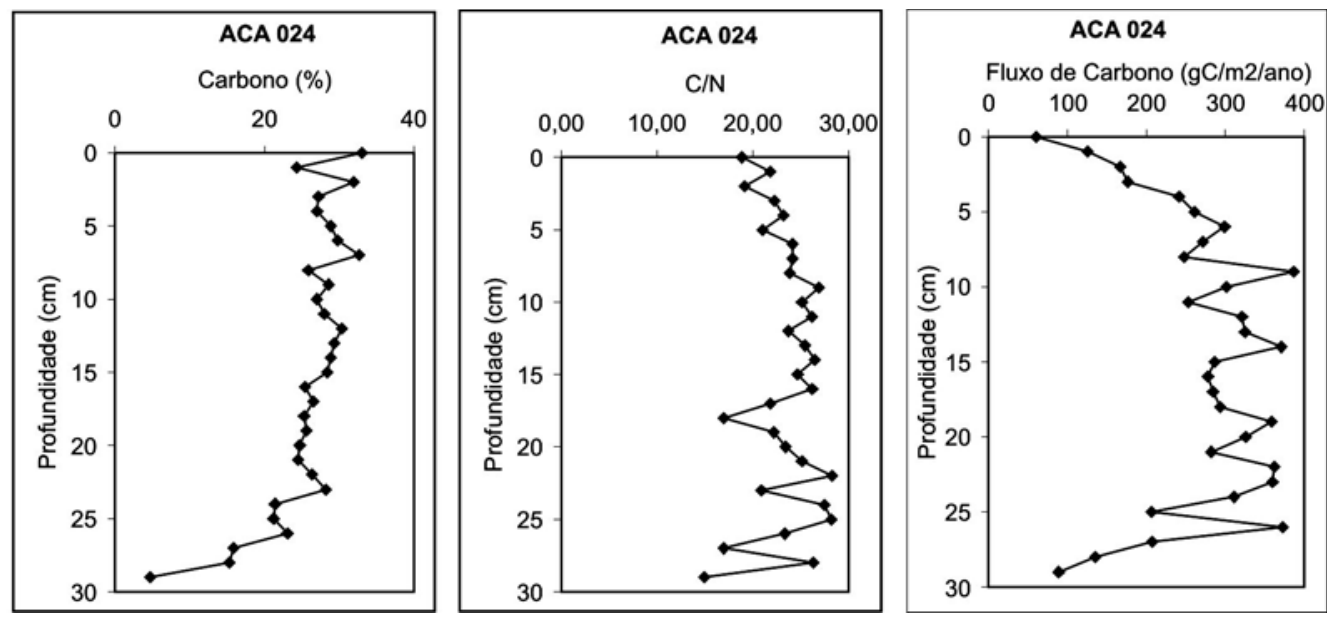

Figura 4. Conteúdo de carbono, razão $\mathrm{C} / \mathrm{N}$ e taxa de acumulação de carbono (fluxo) no testemunho curto ACA 024 do lago Acarabixi. Figure 4. Carbon concentration, C/N ratio and carbon flow in the short core ACA024 colected at lake Acarabixi. 
de carbono o Lago Acarabixi entre 10530 a 9740 anos cal. A.P. volta a apresentar valores médios de acumulação dentro da mesma ordem de grandeza da primeira fase descrita, com uma taxa media de acumulação de 37,3g/m²/ano. Entre 9700 a 9600 anos cal. A.P. novo pulso de acumulação é observado com fluxo médio de $137 \mathrm{~g} / \mathrm{m}^{2} /$ ano, quando a taxa de sedimentação apresenta novamente um aumento considerável $(0,23 \mathrm{~cm} / \mathrm{ano})$. Muito interessante notar que na fase seguinte entre 9550 a 8200 anos cal. A.P. a taxa de acumulação de carbono cai a valores médios de $8,0 \mathrm{~g} / \mathrm{m}^{2} /$ ano mostrando uma tendência gradual de decréscimo do acúmulo entre os valores $19,7 \mathrm{~g} /$ $\mathrm{m}^{2} /$ ano no início de período a aproximadamente $5 \mathrm{~g} /$ $\mathrm{m}^{2}$ /ano no fim deste período em 8200 anos cal. A.P.. Após, entre 8200 a 1520 anos cal. A.P. é observado um hiato de sedimentação. Este hiato é parcialmente coincidente com um paleoclima mais seco com ocorrência de incêndios observado em Carajás que se inicia em 7450 anos cal. A.P.. A partir de 1520 anos cal. A.P. até ca. 645 anos cal. A.P. é observado um fluxo médio de $19,6 \mathrm{~g} / \mathrm{m}^{2} /$ ano. Em Carajás, os fluxo de carbono no Lago N4 começam a subir a partir de 1600 anos cal. A.P. sugerindo uma relação paleoclimática entre os dois eventos. A taxa de acúmulo de carbono no Lago Acarabixi encontra-se abaixo dos demais valores com uma média de $18,2 \mathrm{~g} / \mathrm{m}^{2} /$ ano para o último milênio. Isso sugere que a contribuição da matéria orgânica autóctone no Lago Acarabixi seja menor quando comparado aos outros lagos. Como o Lago Acarabixi, que possui influência de águas pretas, que são pobres em nutrientes e ácidas, sua produção é reduzida, fazendo com que a proporção de matéria orgânica alóctone seja maior (Lima da Costa 2006).

\section{LAGOS EXTERNOS À DINÂMICA FLUVIAL AMAZÔNICA.}

\section{Lagoa da Pata}

Durante os últimos anos, muitos trabalhos realizados em testemunhos de gelo têm mostrado significativas mudanças na temperatura associadas com mudanças na composição da atmosfera. As mais notáveis mudanças se dão entre os períodos glaciais e interglacias (Petit et al. 1999). O comportamento climático em áreas tropicais durante as modificações climáticas globais é por sua vez bastante discutível. Ainda hoje, existem muitas controvérsias sobre a extensão da ocorrência de climas secos na Amazônia. Evidências de fases climáticas secas foram publicadas por diversos autores. Na região de São Gabriel da Cachoeira, o diagrama polínico da Lagoa da Pata mostrou que a vegetação de floresta permaneceu com elementos arbóreos, havendo substituição de elementos de clima frio durante o último glacial (Colinvaux et al. 1996). Este trabalho demonstrou que apesar de mudanças na composição polínica não houve uma substituição da fisionomia florestal para uma fisionomia de savana como observado em Carajás, durante o último glacial (Absy et al. 1991). Entretanto, as interpretações paleoclimáticas de Colinvaux et al. (1996) não levam em conta os processos paleolimnológicos do ambiente lacustre que podem ser excelentes indicadores de mudanças no balanço hídrico local.

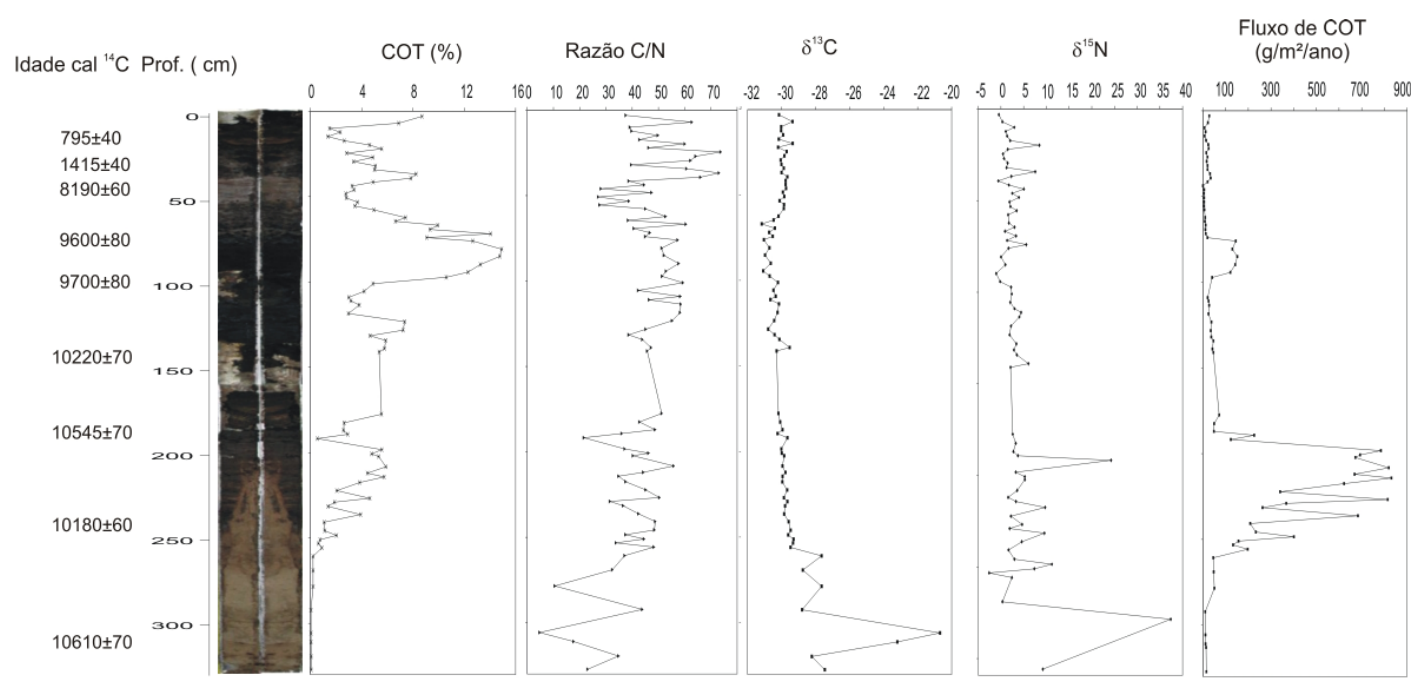

Figura 5. Parâmetros orgânicos e fluxos de carbono estimados para o testemunho ACA02/03.

Figure 5. Organic parameters and estimated carbon rates of the core ACA02/03. 
No presente trabalho é apresentado um perfil sedimentar da Lagoa da Pata, onde foram integrados valores de concentração e fluxos de carbono bem como a razão $\mathrm{C} / \mathrm{N}$, distribuição dos isótopos estáveis $\delta^{13} \mathrm{C}$ e $\delta^{15} \mathrm{~N}$, e fluxos de carbono. Os dados obtidos foram comparados com dados secundários, referentes às variações paleoclimáticas e atmosféricas em registros de gelo Antártico.

Três fases (Figura 6) relacionadas às características sedimentares orgânicas e inorgânicas podem ser observadas. Entre aproximadamente 45000 e 40000 A.P. idade ${ }^{14} \mathrm{C}$ a taxa de acumulação de carbono é alta, associada provavelmente a um nível lacustre alto. De 40000 a 25000 A.P. idade ${ }^{14} \mathrm{C}$ observa-se uma redução da taxa de acumulação de carbono provavelmente associado a um abaixamento do nível hídrico. Os sedimentos nesta fase apresentam baixos teores de COT. A relação $\mathrm{C} / \mathrm{N}$ é alta associada provavelmente a um aporte de material lenhoso em detrimento ao algal. Baixos valores de $\delta^{13} \mathrm{C}$ (em torno de $-32 \%$ ) confirmam um aporte de matéria orgânica tipo $\mathrm{C}_{3}$ (lenhosas arbóreas). $\mathrm{O}$ fluxo de carbono nesta fase é de $2,20 \mathrm{gC} / \mathrm{m}^{2} /$ ano. A segunda fase, entre 25000 AP idade ${ }^{14} \mathrm{C}$ a 18000 AP idade ${ }^{14} \mathrm{C}$ caracterizando último máximo glacial é uma fase de mais baixa produtividade com praticamente interrupção na taxa de sedimentação (Santos et al. 1999, Barbosa et al. 2004, Cordeiro et al. 2004). O carbono nesta fase apresenta-se baixo em torno de $4 \%$ com seus fluxos bastante diminuídos em torno de $0,121 \mathrm{gC} / \mathrm{m}^{2} /$ ano. Os valores de $\delta^{13} \mathrm{C}$ ficam em torno de -30 a $-26 \%$ oo que caracteriza uma contribuição de matéria orgânica originaria de vegetação de gramínea $\left(\delta^{13} \mathrm{C}=-17 \%\right.$ oo aumentando de cinco unidades o sinal de $\delta^{13} \mathrm{C}$. Entre 18000 A.P. idade ${ }^{14} \mathrm{C}$ a aproximadamente 9000 A.P. idade ${ }^{14} \mathrm{C}$ inicia-se um incremento da produtividade lacustre (carbono em torno de $36 \%$ ). O $\delta^{13} \mathrm{C}$ médio de $-32 \%$ indica material lenhoso ou fitoplanctônico, entretanto a diminuição do $\mathrm{C} / \mathrm{N}$ sugere influência fitoplanctônica sobre a matéria orgânica. Neste período o nível do lago subiu incrementando a produção primaria do sistema. O fluxo de carbono nesta fase aumenta substancialmente em relação à fase precedente com uma média de $4,16 \mathrm{gC} / \mathrm{m}^{2} / \mathrm{ano}$. Portanto o incremento da produtividade após o fim do período glacial máximo é evidente com uma ascensão dos fluxos de carbono cerca de 30 vezes entre o período glacial e o período interglacial subseqüente.

Dentro do período referente aos registros obtidos na Lagoa da Pata, ca de 45000 A.P. idade ${ }^{14} \mathrm{C}$, foi observado que o fluxo de carbono variou em função das mudanças globais de temperaturas observadas no testemunho de Gelo em Vostock (Antártica; Petit et al. 1999), provavelmente relacionado às variações do nível lacustre (Figura 7).

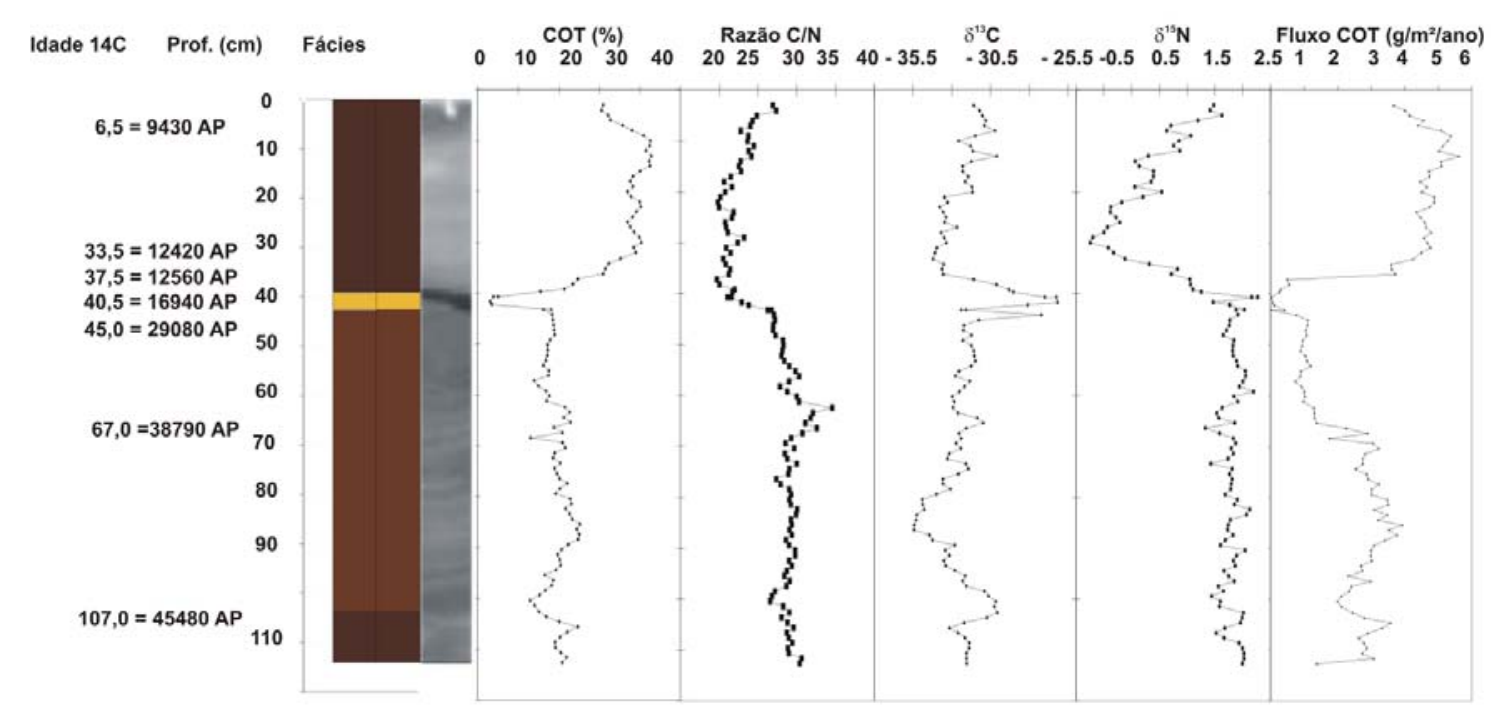

Figura 6. Parâmetros orgânicos e fluxos de carbono estimados para o testemunho LPTV. Figure 6. Organic parameters and estimated carbon rates of the core LPTV. 


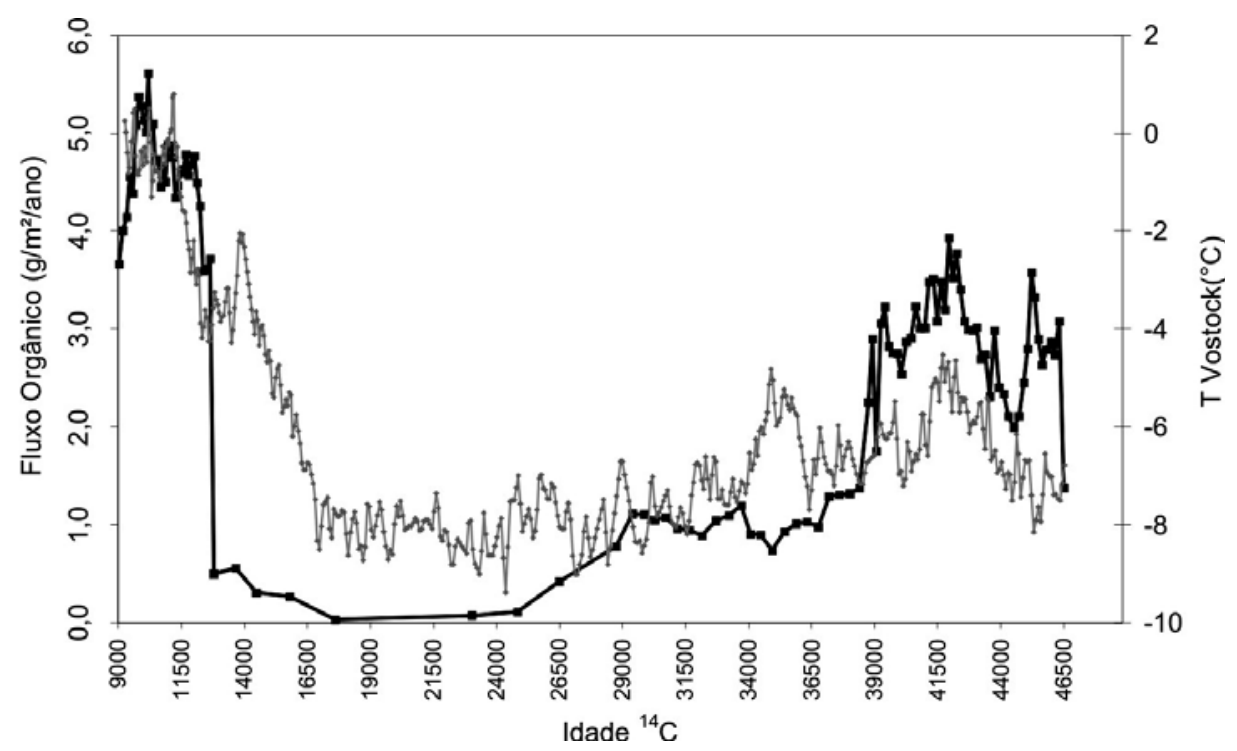

Figura 7. Fluxo orgânico ao longo dos últimos 46500 anos A.P e a temperatura calculada a partir da relação deutério x hidrogênio no testemunho de Vostock (Antártica; Petit et al. 1999).

Figura 7. Organic flow over the last 46,500 years B.P and temperature estimated based on the deuterium / hydrogen ratio of the Vostock core, Antartic

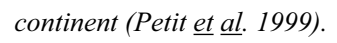

\section{Carajás}

Um estudo paleolecológico correspondendo a 11800 anos da história ambiental da região de Carajás (PA) foi realizado baseado na estimativa de fluxos de deposição de material biogênico em ecossistema lacustre (Figura 8).

Através da interpretação dos processos de sedimentação foram identificadas cinco fases.

- 11800 anos cal. A.P. (CSN 93/4 core, Cordeiro et al. 2008) a 7600 anos cal. A.P. fase seca com baixas concentrações de partículas carbonizadas e apresentando os baixos valores de fluxos de carbono com uma média de $1,74 \mathrm{~g} / \mathrm{m}^{2} /$ ano.

- 7600 a 4700 anos cal. A.P. Fase seca com alta ocorrência de incêndios. Fase de intenso fluxo de carvão. Os altos valores de $\mathrm{C} / \mathrm{N}$ e incremento no fluxo de carbono orgânico chegando a um valor médio para esta fase de $6,12 \mathrm{~g} / \mathrm{m}^{2} /$ ano e os maiores fluxos de partículas carbonizadas demonstram que a matéria orgânica depositada foi altamente influenciada pelos aportes de carvão provavelmente de origem atmosférica considerando seu pequeno tamanho (Média $=$ $15,5 \mu \mathrm{m})$. Os baixos valores de clorofila sedimentar sugerem que o nível do lago era baixo.

- 4700 a 2800 anos cal. A.P. Fase úmida. Este parece ser um período úmido com o menor fluxo de microcarvões encontrado em 2650 anos A.P. Observa-se breve flutuação seca em 3500 anos cal.
A.P. Observa-se um incremento na produtividade do sistema atestado pelo incremento do fluxo de clorofila indicando um aumento de nível do lago. Os valores de fluxo de clorofila sedimentar aumentam à medida que o fluxo de carvão vegetal diminui.

- 2800 a 1300 anos cal. A.P. Fase de incremento do nível do lago, acumulação de carbono aumenta em relação à fase antecedente chegando a $4,04 \mathrm{~g} / \mathrm{m}^{2} / \mathrm{ano}$. Deposição de partículas carbonizadas é baixa.

- Fase seca de pequenas proporções de 1300 a 150 anos cal. A.P. O clima seco nesta fase parece não ter diminuído a produtividade do sistema lacustre, entretanto o incremento da produtividade que era uma característica da fase anterior diminui consideravelmente. É observado um aumento de fluxo de carvão vegetal em 730 anos cal. A.P. O fluxo de carbono chega a $10,5 \mathrm{~g} / \mathrm{m}^{2} /$ ano atestando que apesar do clima favorecer a ocorrência de incêndios florestais a deposição de carbono se manteve em níveis elevados em relação às fases anteriores provavelmente devido a um aumento de sazonalidade.

- Fase úmida atual - 150 anos cal. A.P. até a atual - Fase úmida atual com altos fluxos de clorofila sedimentar e fluxos de carbono orgânico chegando a $21,3 \mathrm{~g} / \mathrm{m}^{2} /$ ano. Os fluxos de carvão são baixos. A grande ocorrência de incêndios nas fases secas identificadas comprova que os incêndios florestais foram eventos determinantes na história dos ecossistemas dessa região por um grande intervalo de tempo. 


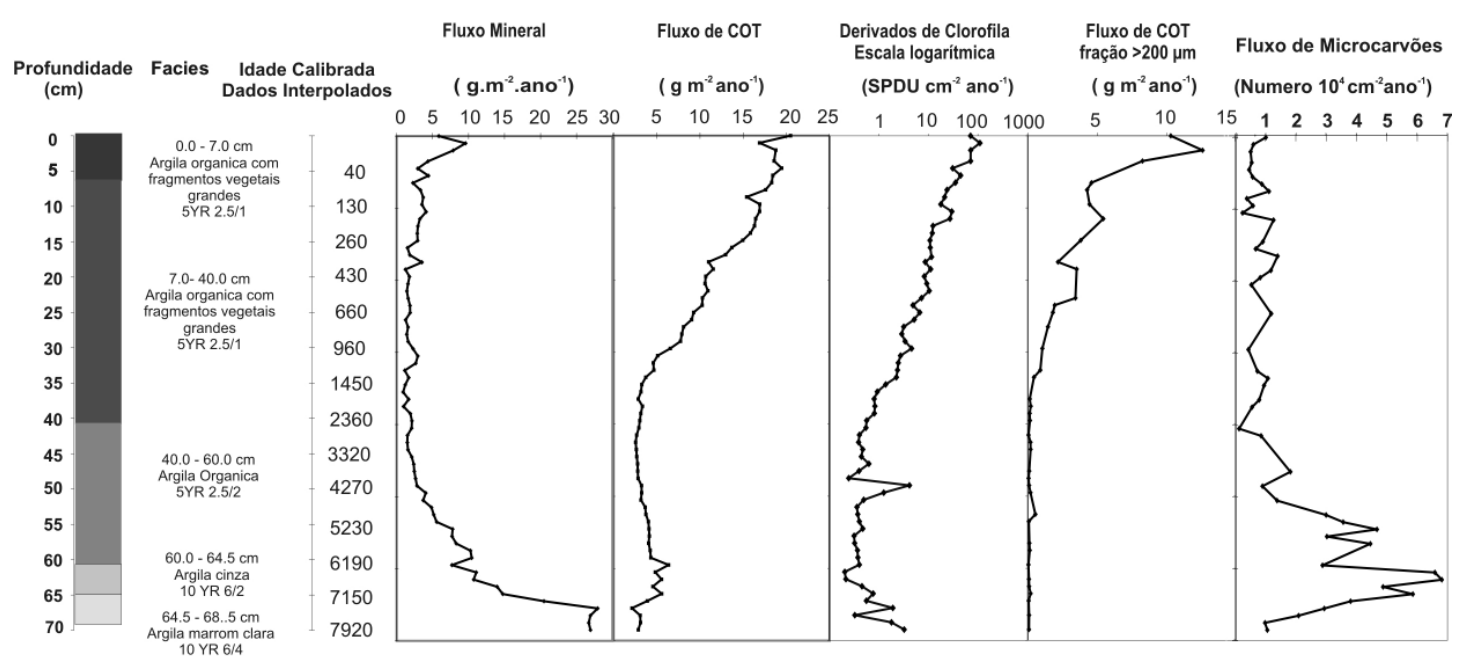

Figura 8. Parâmetros orgânicos e fluxos de carbono estimados para o testemunho CSN93/3.

Figura 8. Organic parameters and estimated carbon rates of the core CSN93/3.

\section{Humaitá}

Nesta região foram demonstradas mudanças na dinâmica da vegetação ao longo do Holoceno determinado por estudo isotópico da matéria orgânica do solo (Pessenda et al. 1998). A região de estudo é caracterizada por uma forte tendência de transição da floresta tropical ombrófila densa pela vegetação do tipo campo-cerrado. Nos últimos anos, os ecossistemas naturais da região vêm sendo substituídos por áreas destinadas ás pastagens e ao cultivo da soja fazendo parte de uma das áreas de maior pressão pela expansão da fronteira agrícola denominado "Arco do Desmatamento" da Amazônia que vai do Estado do Acre, passando pelo Estado de Rondônia em direção ao sul do Estado do Pará e norte do Estado do Mato Grosso. Com o avanço da fronteira agroindustrial liderada pelo plantio da soja e da pecuária ao longo das últimas quatro décadas, poderão ser apagados determinados registros de ecossistemas passados, gerando lacunas face à compreensão de todo o passado biótico e climático do "cerrado" amazônico.

A utilização de indicadores biogeoquímicos na reconstrução paleoambiental na região de Humaitá (AM), através da análise do fluxo de material biogênico e das análises isotópicas e radiocarbônicas, possibilitou reconstituir as condições paleoclimáticas e o cenário ambiental da região de Humaitá (AM) no Holoceno, nos últimos 4800 anos (Figura 9). A interpretação temporal à cerca das transformações do material biogênico em função de possíveis intervalos climáticos diferenciados indicou cinco fases climáticas sendo elas:
- Fase seca com alta ocorrência de incêndios de 4800 a 4600 anos cal. A.P. Nesta fase a média para o período de carbono orgânico total apresenta-se com o mais baixo valor quando comparado às outras fases do perfil (1,03\%). A relação $\mathrm{C} / \mathrm{N}$ fica em torno de 14,80 atestando uma mistura de fontes. $\mathrm{O}$ valor médio de $\delta^{13} \mathrm{C}(\sim 23,8 \%)$ caracteriza uma mistura de fonte de matéria orgânica $(\mathrm{C} 3+\mathrm{C} 4)$. O valor médio de $\delta^{15} \mathrm{~N}$ é o mais elevado entre as fases indicando processo de retrabalhamento da matéria orgânica.

- Fase úmida com pouca ocorrência de incêndios de 4600 a 4250 anos cal. A.P. caracterizada por valores relativos de carbono orgânico altos chegando a 5,51 \%. A relação $\mathrm{C} / \mathrm{N}$ decresce sugerindo um maior alagamento do sistema com incremento de vegetação algal. Um decréscimo do valor médio de $\delta^{15} \mathrm{~N}$ é observado. Os valores de $\delta^{13} \mathrm{C}$ são próximos aos observado para fase antecedente $\left(\delta^{13} \mathrm{C}=24,0\right)$. Os fluxo de carbono orgânico total aumentaram consideravelmente chegando a um valor médio de $11,3 \mathrm{gC} / \mathrm{m}^{2} /$ ano.

- Fase úmida de transição de intensa atividade erosiva de 4250 a 3500 anos cal. A.P. com pouca ocorrência de incêndios. Observa-se um decréscimo dos valores de carbono orgânico em relação à fase anterior (3,58 \%). $\mathrm{O}$ valor médio da relação $\mathrm{C} / \mathrm{N}$ de 14,4 aumenta em relação à fase anterior sugerindo um aporte maior de matéria orgânica de origem vascular. Um incremento do valor médio de $\delta^{15} \mathrm{~N}\left(\delta^{15} \mathrm{~N} \sim 3,54\right.$ $\%$ ) é observado. Os valores de $\delta^{13} \mathrm{C}$ voltam a aumentar $\left(\delta^{13} \mathrm{C}=-23,8 \%\right.$ ). Os fluxo de carbono orgânico total diminui consideravelmente apresentando valor médio de $7,58 \mathrm{gC} / \mathrm{m}^{2} / \mathrm{ano}$. 
- Fase seca, com pouca ocorrência de incêndios de 3500 a 400 anos cal. A.P.. O valor médio de COT para este período foi de $4,30 \%$ com aumento de $\delta^{13} \mathrm{C}$ de $\sim 1,3 \%$ em seu valor médio $\left(\delta^{13} \mathrm{C}=-22,4 \%\right.$ ) . Cabe ressaltar que 1660 idade calibrada AP ocorre um aumento considerável no valor de $\delta^{13} \mathrm{C}$ chegando a -19,3\%o. Considerando que o valor médio de $\mathrm{C} / \mathrm{N}$ aumenta consideravelmente em relação a fase precedente chegando a 22,4 pode-se deduzir que esta variação isotópica de carbono pode estar relacionada a um aumento de aporte de matéria orgânica de gramíneas (C4). O fluxo médio de COT diminui ainda mais apresentando valor de $1,13 \mathrm{gC} / \mathrm{m}^{2} / \mathrm{ano}$, o valor mais baixo entre as diferentes fase identificadas. Isto sugere uma diminuição do nível hídrico com favorecimento ao desenvolvimento de vegetação do tipo $\mathrm{C} 4$.

- Fase úmida com alta ocorrência de incêndios de 400 anos cal. A.P. até o presente. Os valores de COT ficam em torno de 3,09\%. A relação $\mathrm{C} / \mathrm{N}$ abaixa indicando aumento de processo de alagamento. Os valores de $\delta^{13} \mathrm{C}$ decrescem $\sim 1.5 \%$ em seu valor médio $\left(\delta^{13} \mathrm{C}\right.$ $=-23,8 \%$ ). $\mathrm{O}$ valor médio de $\delta^{15} \mathrm{~N}$ aumenta consideravelmente $\left(\delta^{15} \mathrm{~N} \sim 5,39 \%\right)$. Os fluxo médio de carbono orgânico total aumenta consideravelmente apresentando valor médio de $12,65 \mathrm{gC} / \mathrm{m}^{2} /$ ano.

No registro do testemunho HUM 97/5 (Humaitá AM), encontrou-se uma fase de principal ocorrência dos incêndios há 300 anos cal.A.P.; com fluxo de 78700 partículas $/ \mathrm{cm}^{2} /$ ano; e uma segunda fase marcada por baixas concentrações de carvões: 700 partículas $/ \mathrm{cm}^{2} /$ ano em 1000 anos cal. A.P.; 1300 partículas $/ \mathrm{cm}^{2} /$ ano em 1400 anos cal. A.P.; 2300 partículas/ $\mathrm{cm}^{2} /$ ano em
3850 anos cal. A.P., sendo detectados maiores valores no topo e na seção basal do testemunho analisado. Os valores de $\delta^{13} \mathrm{C}$ obtidos no perfil sedimentares analisados (HUM 97/5), indicam mudanças do tipo de vegetação no período estudado, sugerindo que os limites floresta-cerrado e campo possam ter sofrido alterações durante a transição do Holoceno Médio para o Holoceno Superior.

\section{Lago Caracaranã e a evolução do contato savana- floresta no lavrado de Roraima}

A determinação dos fluxos dos marcadores analisados no presente estudo (Figura 10), permitiu a interpretação das mudanças paleoambientais que levaram à alteração dos padrões de sedimentação pretéritos do Lago Caracaranã. O significado da variação dos fluxos de carbono está diretamente relacionado às condições ambientais experimentadas pelos ecossistemas, permitindo a reconstituição dos possíveis cenários, onde as mudanças paleoclimáticas desempenharam papel fundamental.

Os fluxos de carbono (COT) e micro-carvões encontram-se relacionados durante o período de aparecimento de lagos no início do Holoceno (fase I), assim como no Holoceno Inferior (fase II) e entre este e o Holoceno Médio (fase III). Durante todo esse período, compreendido entre 11300 e 7600 anos cal. A.P., a principal fonte de carbono foi a produção de fragmentos de carvão e fragmentos ligno-celulósicos, a maior parte com dimensões acima de $100 \mu \mathrm{m}$, originados da vegetação palustre desenvolvida as margens do lago com drenagem incipiente e produção de

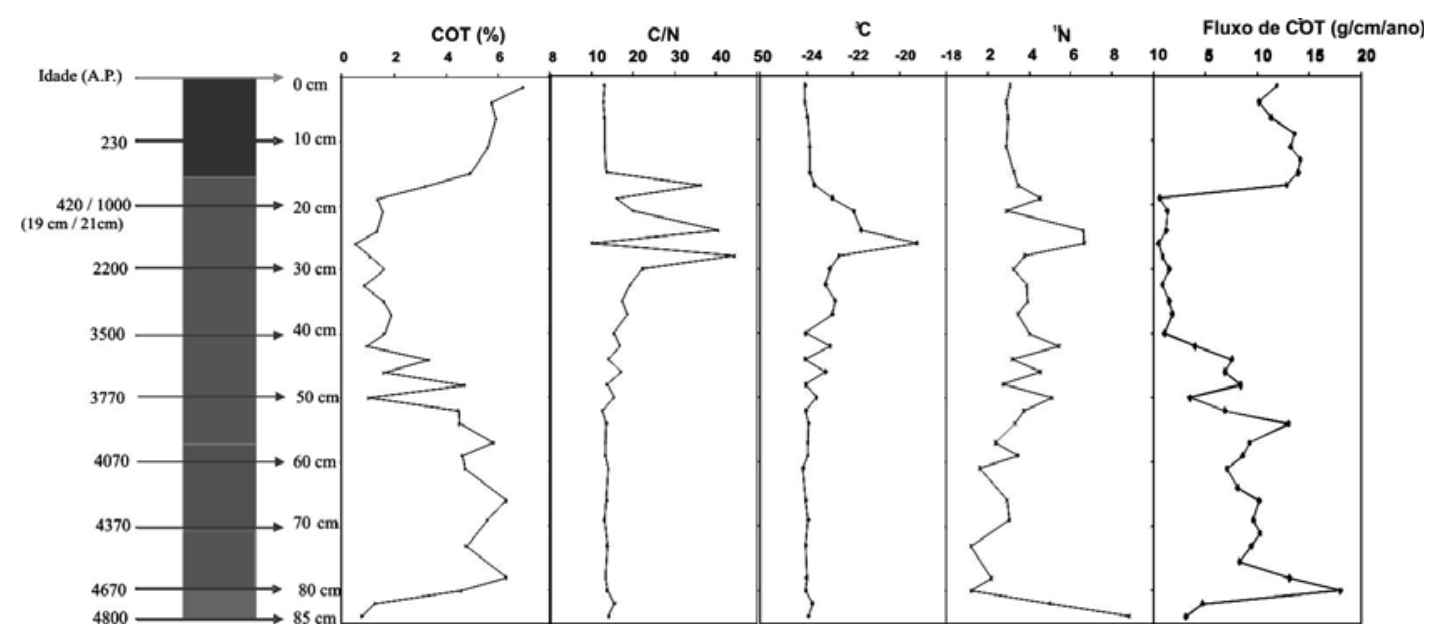

Figura 9. Parâmetros orgânicos e fluxos de carbono estimados para o testemunho Hum97/5. Figure 9. Organic parameters and estimated carbon rates of the core Hum97/5. 


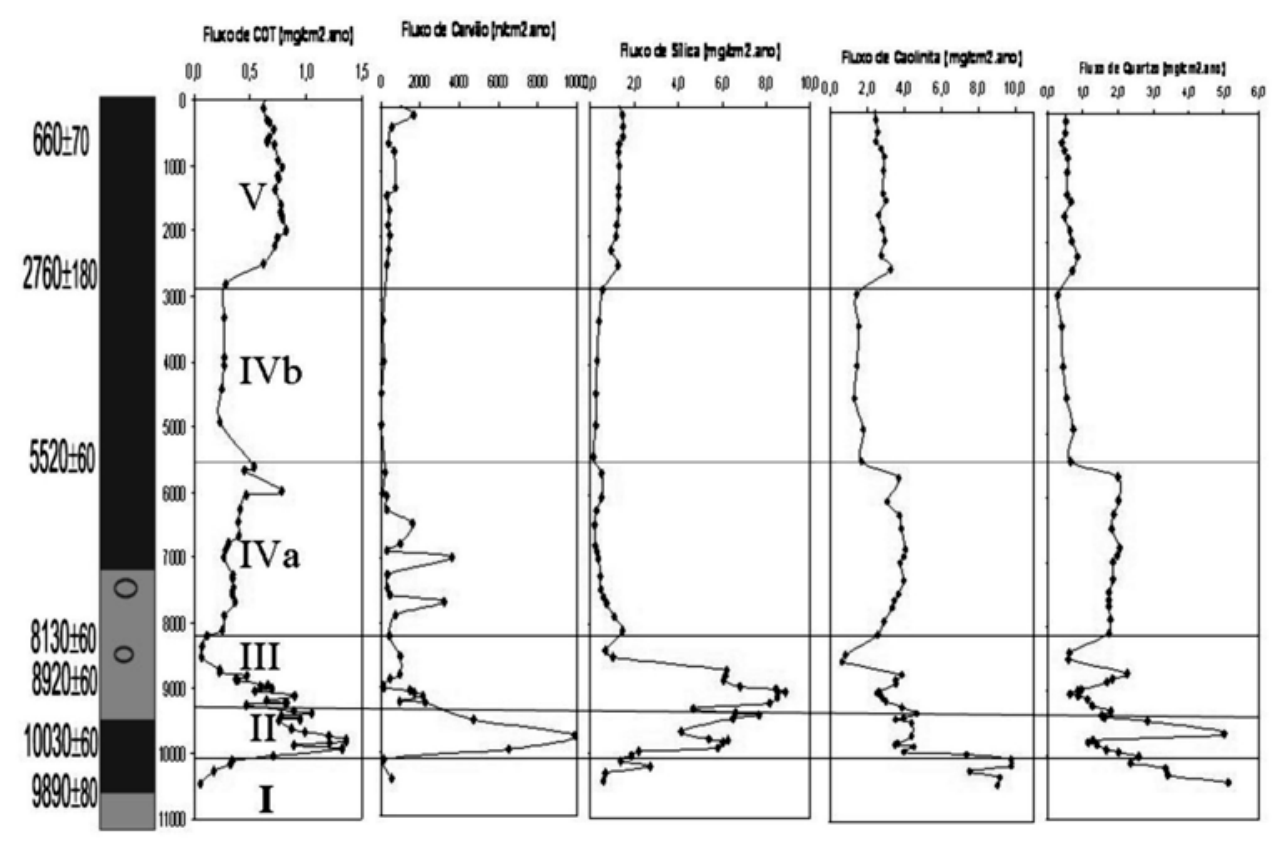

Figura 10. Fluxos de Carbono, Carvão e de Minerais (sílica, caolinita e quartzo) ao longo do Holoceno (idades calibradas interpoladas) no testemunho RR94-9.

Figure 10. Flow rates of carbon, coal and minerals (silica, kaolinite and quartz) over the Holocene (interpolated calibrated ages) of the core RR94-9.

esponjas típicas de ambientes rasos (Cândido et al. 2000). Por outro lado, nas fases correspondentes a transição do Holoceno Médio ao Superior (IVa, IVb) entre 7600 e 2000 anos cal. A.P. e na fase atual (V) nos últimos 2 mil anos, a correspondência entre os carvões e o COT foi menos evidente. No Holoceno médio foi observada a presença de picos de fluxo de carvão, com menores dimensões, sendo que os principais picos ocorreram em 7500, 7100 e 6800 anos cal. A.P. A partir daí, os fluxos de carvão praticamente extinguiram-se, voltando a apresentar um modesto incremento a partir de cerca de 1500 anos cal. A.P. Por outro lado, os fluxos de carbono que permaneceram com valores quase constantes durante todo o Holoceno Médio (em torno de $3 \mathrm{~g} / \mathrm{m}^{2} / \mathrm{ano}$ ), experimentaram um incremento considerável a partir dos últimos 2 mil anos alcançando valores de até $8 \mathrm{~g} / \mathrm{m}^{2} /$ ano, com ligeiro decréscimo em direção ao presente. Esse comportamento provavelmente se deve ao aumento da presença de frações ligno-celulósicas relacionadas ao maior desenvolvimento atual da vegetação no entorno do lago.

No contato floresta-savana de Roraima, o aparecimento dos lagos e brejos na região, em conseqüência do clima mais úmido atual, parece ser recente. Isto está de acordo com os vários índices geomorfológicos de dominância de clima seco nesta região e explica, em parte, a juventude da rede de drenagem, ainda pouco desenvolvida. Os registros da sedimentação, em lagos situados em áreas do contato florestasavana de Roraima, possibilitaram pontuar as principais características da dinâmica ambiental ocorridas durante o Holoceno. A sucessão das unidades sedimentares descritas sublinha a grande variabilidade destes ambientes, situados ao nível da bacia do Lago Caracaranã. Essas modificações ambientais, cuja força motriz neste intervalo de tempo é o clima, alteraram substancialmente a qualidade do material mineral e biogênico depositado.

$\mathrm{O}$ estabelecimento da rede de drenagem e lagos se deu no início do Holoceno, quando os mais antigos corpos de água e o padrão de drenagem por veredas se originaram. No entanto, devido às altas taxas de insolação e evaporação e a drenagem endorréica pouco desenvolvida, a maioria deles não formou lagos perenes, desaparecendo na estação seca. Desta forma, quase todos os sistemas lênticos, localizados nos campos do rio Branco, só possuem registros sedimentares contínuos a partir do Holoceno Superior, quando a sazonalidade do clima foi atenuada. A interpretação dos padrões de sedimentação permitiu identificar mudanças climáticas, que definiram as cinco principais fases paleoclimáticas da evolução ambiental de Roraima durante o Holoceno, com diferentes implicações sobre a dinâmica do contato floresta-savana. 
Apesar da fase do ótimo climático holocênico estar bem identificada neste estudo, a mesma não conduziu a formação de lagos profundos com produção fitoplanctônica lacustre. Isto se deveu a atuação de um paleoclima caracterizado por prolongada estação seca e baixa razão $\mathrm{P} / \mathrm{E}$, que impediu a acumulação de água nas bacias. Isto não significa, necessariamente, que não houve crescimento de vegetação arbórea adaptada a este estresse hídrico. No entanto, são necessários, ainda, dados palinológicos com maior resolução temporal para se esclarecer quais eram as principais formações vegetais do ótimo climático. Ainda assim, pode-se concluir que o clima atual é o mais úmido desde o último máximo glacial, com favorecimento ao desenvolvimento das florestas, enquanto muitos fragmentos de savanas abertas, relictos do clima seco do Pleistoceno e/ou Holoceno Médio, tendem a ser progressivamente substituído por florestas.

A ocorrência de vários incêndios entre 100009000 e $8000-6000$ cal. A.P. comprova que estes foram determinantes na história dos ecossistemas de floresta e savana dessa região, durante um longo período do Holoceno. Estes eventos periódicos estão relacionados às oscilações paleoclimáticas, que tiveram grande impacto sobre a distribuição das espécies de savana e floresta, estabelecendo em grande parte, o limite atual entre os ecossistemas (Prance 1992). A magnitude e freqüência dos eventos de queima, ocorridos na região de Roraima, durante as fases secas - ou mesmo úmidas - do Holoceno, podem ter introduzido alterações no ciclo do carbono, a partir da liberação dos estoques contidos na biomassa vegetal para os sistemas atmosférico e oceânico. Isto provavelmente ocorreu no Holoceno Tardio, devido à ignição da vegetação que aumentou muito os fluxos de carbono, associado ao carvão, concentrou os gases estufa na atmosfera e, assim, contribuiu para o aquecimento global que caracterizou o início do interglacial atual (Saldarriaga \& West 1986, Indermüle et al. 2001).

Registros sedimentares de mudanças ambientais ao longo do processo de colonização da Amazônia e mercúrio em área de intenso uso da terra na Amazônia brasileira (Alta Floresta, MT).

A região amazônica tem sofrido nos últimos 20 anos um acelerado processo de colonização. Este processo de transformação do ambiente se faz ainda hoje de forma rápida e desordenada. As atividades garimpeiras e trans- formação de vastas áreas florestais em pastagem com o uso do fogo são os principais impactos sobre o ambiente. A acumulação de carbono é discutida neste trabalho em função das mudanças econômicas regionais bem como em relação às mudanças macroeconômicas.

A área urbana de Alta Floresta, distante $800 \mathrm{~km}$ de Cuiabá foi implantada em 1976 pela iniciativa privada, visando a colonização dirigida na Região do Alto Tapajós (Hacon 1996). A cidade que teve seu núcleo urbano iniciado em 1980 teve um rápido processo de colonização na década de 80 em função da atividade garimpeira e exploração madeireira. $\mathrm{O}$ testemunho At1a (9॰58'S e $\left.55^{\circ} 49^{\prime} \mathrm{W}\right)$ foi coletado com amostrador de pistão na região central da barragem formada a partir da construção em 1978 da rodovia $\mathrm{Br}$ 208. A cronologia dos extratos foi determinada a partir da taxa de sedimentação calculada a partir do contato litológico em $10,0 \mathrm{~cm}$, onde o sedimento mudou de uma fácies mineral para uma fácies orgânica (Figura 11), correspondente respectivamente ao solo original e ao ambiente lacustre formado a partir do barramento do curso d'água. Considerando-se a data de construção da estrada em 1978 e que o testemunho foi coletado no ano de 1996, tem-se a taxa de sedimentação calculada da seguinte forma: ts $=10,0 \mathrm{~cm} / 18$ anos $=0,55 \mathrm{~cm} /$ ano.

As análises química e microscópica dos indicadores de queimadas apresentaram-se bem correlacionados: 0,93 , para $\mathrm{n}=8$, entre carbono grafítico e concentração de área das partículas e 0,80 , para $\mathrm{n}=8$, entre carbono grafítico e número de partículas.

Os fluxos de carvão expressos em fluxo de número de partículas bem como os fluxos do carbono grafítico mostram um aumento da deposição nos ano de 1989 e principalmente após o ano de 1993 (Figura 12). Entre os anos de 1990 a 1992 ocorreu uma diminuição dos fluxos número de partículas e carbono grafítico.

A concentração de Hg no testemunho At1a mostra concentrações de background em torno de 50 to $70 \mu \mathrm{g}$ Hg. $\mathrm{kg}^{-1}$ nos primeiros $30 \mathrm{~cm}$. Um grande incremento nos primeiros $10 \mathrm{~cm}$ centímetros foi observado, com um máximo de $175 \mu \mathrm{g} \mathrm{Hg} . \mathrm{kg}^{-1}$ na camada superficial. O fluxo médio entre 1978 a 1998 foi de $510 \mu \mathrm{g} / \mathrm{m}^{2} /$ ano com máximo fluxo de $825 \mu \mathrm{g} / \mathrm{m}^{2} /$ ano em 1993 e mínimo fluxo $\mathrm{de} 320 \mu \mathrm{g} / \mathrm{m}^{2} /$ ano em 1981 . Estes fluxos são altos quando comparados aos fluxos achados em áreas remotas, considerando que as mudanças nos níveis background destas áreas ficaram em torno de $1,7 \mathrm{a} 5,3 \mu \mathrm{g} / \mathrm{m}^{2} / \mathrm{ano}$ (Santos et al. 2000, Lacerda et al. 1999). 


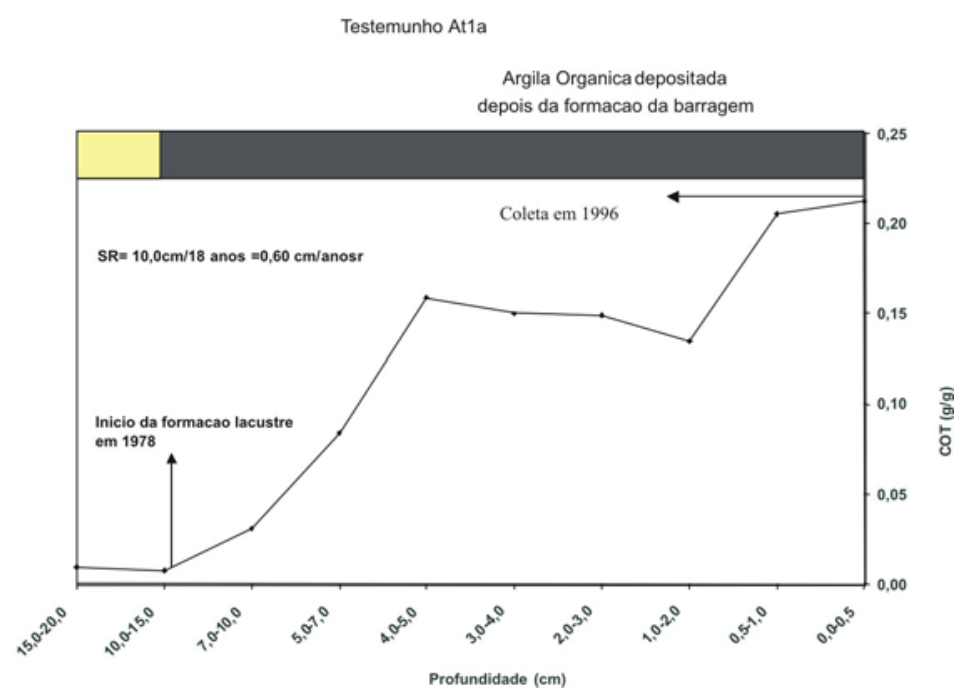

Figura 11. Carbono orgânico no testemunho At1a. Os pontos assinalados serviram de base para o cálculo das taxas de sedimentação. Figure 11. Organic carbon in the core Atla. The indicated areas were used to calculate the sedimentation rates.

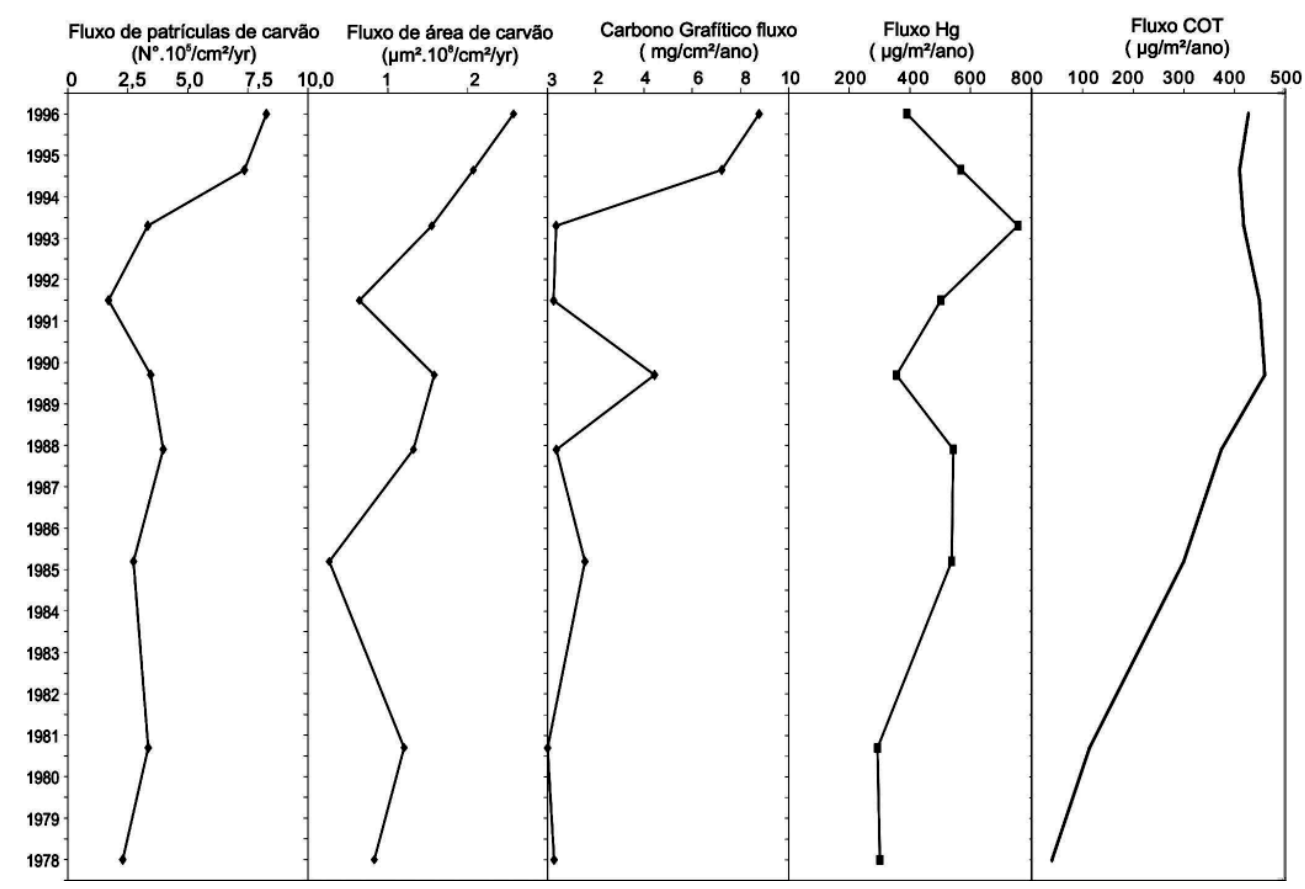

Figura 12. Indicadores de mudanças ambientais em Alta Floresta. Acumulação de indicadores de queimada ${ }^{\circ}$ de partículas de carvão, área de partículas de carvão, carbono grafítico, mercúrio e carbono orgânico total.

Figure 12. Indicators of environmental changes in Alta Floresta. Accumulation of forest burn indicators, number of coal particles, coal particles area, graphitic carbon, mercury and total organic carbon.

Na região amazônica geralmente o processo de colonização ocorre depois da implementação de uma estrada (Fearnside 1987). Os fluxos de mercúrio e material proveniente de queimadas mostraram baixos valores no inicio da ocupação humana. No fim da década de 70 os fluxos de carvões eram baixos e o tamanho das partículas de carvões era pequeno, sugerindo uma distante área fonte. Neste período o fluxo de mercúrio era baixo. No início da década de 80 ocorreu um incremento nos incêndios florestais e atividade garimpeira. A deposição indicadora de queimada e de mercúrio proveniente da atividade garimpeira apresentou dois padrões de evolução. Incêndios florestais aumentaram lentamente até 1989 quando ocorreu um incremento substancial nos fluxos de carvões. Depois, entre 1990 ate 1992 um drástico decréscimo nos indicadores de queimada foi observado. Este período coincide com o ano de retração na 
economia (FGV 2000) devido aos efeitos decorrentes a implementação do plano econômico do governo Fernando Collor de Mello. Este plano foi marcado pela redução do produto interno bruto entre 1990 ate 1992 (Figura 13). As atividades econômicas dos agricultores são sensíveis a drásticas mudanças econômicas como as mudanças na taxa de juros nos mercados de capitais, retornam de outros investimentos, subsídios do governo para credito agrícola, taxa de inflação, e mudanças do preço da terra (Fearnside 1999). Neste caso, um decréscimo no capital circulante durante o plano Collor provavelmente induziu a um decréscimo dos investimentos em desmatamento. Observa-se também uma diminuição da taxa de acumulação de carbono após este período.

Duas diferentes tendências foram observadas no registro sedimentar que engloba o processo de colonização em Alta Floresta. O registro sedimentar mostrou que os indicadores de queima, que representam a atividade agrícola estão ligados aos aspectos macroeconômicos da economia brasileira. Em relação ao mercúrio o padrão de deposição parece estar relacionado com a produção de ouro independente da evolução macroeconômica. Foi observado no registro sedimentar a substituição do modelo econômico numa região de intensa mudança do uso da terra que modificou o tipo de impacto ambiental na região. No inicio da colonização, intensas atividades garimpeiras foram sendo substituídas por atividades agropecuárias com intenso uso do fogo como transformador da paisagem. Ambos os processos de colonização marcam uma rápida transformação da paisagem com grande influência sobre o sistema límnico estudado.
Estas influências podem ser dimensionadas quando observam-se altas taxas de acumulação de carbono desde o início do processo de colonização. Estas taxas de acumulação são as mais altas quando comparadas com as outras áreas estudadas.

\section{DISCUSSÃO}

As taxas de acumulação de carbono em lagos comumente aumentam com mudanças climáticas mais quentes e úmidas (particularmente, grandes lagos superfíciais). A influência antropogênica aumenta a produção e a preservação de carbono orgânico nas bacias lacustres (freqüentemente por um fator de 3-4). Portanto a contribuição dos lagos e reservatórios artificiais como sumidouro de carbono de origem humana não deve ser negligenciado (Einsele et al. 2001). Os valores de taxas de acumulo observados para os sítios estudados denotam altas taxas de acúmulo principalmente pára área de várzea. Eventos abruptos de sedimentação orgânica foram observados para as várzeas de Acarabixi (Rio Negro) e Curuaí (Rio Amazonas) demonstrando que processos hidrológicos associados a diferentes condições paleoclimáticas podem alterar drasticamente as entradas de carbono no sistema. Moreira-Turcq et al.(2004) calcularam para a várzea Grande do Curuai uma taxa de acúmulo médio de carbono de $100 \mathrm{~g} / \mathrm{m}^{2} /$ ano para os últimos cem anos. Outras várzeas do Rio Amazonas apresentam taxas de acúmulo de carbono semelhantes: $44 \mathrm{~g} / \mathrm{m}^{2} /$ ano no lago Jacaretinga (Devol et al. 1984, apud Moreira-Turcq et al. 2004), $137 \mathrm{~g} / \mathrm{m}^{2} /$ ano no Lago Calado (SmithMorrill 1987, apud Moreira-Turcq et al. 2004), e 28g/

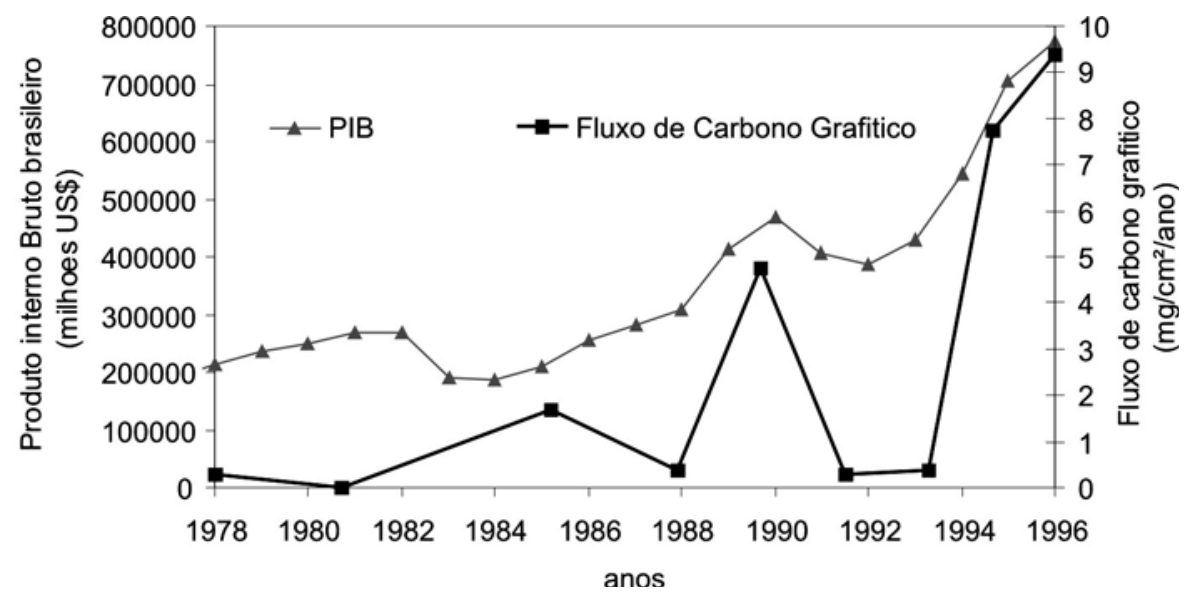

Figura 13. Fluxo de carbono grafítico e o Produto Interno Brasileiro.

Figure 13. Graphitic carbon flow and Brazilian Domestic Product. 
m²/ano no Lago Cristalino (Devol et al. 1984, apud Moreira-Turcq et al. 2004). A taxa de acúmulo de carbono no Lago Acarabixi encontra-se abaixo dos demais valores com uma média de $19,6 \mathrm{~g} / \mathrm{m}^{2} /$ ano para o último milênio. Isso sugere que a contribuição da matéria orgânica autóctone no Lago Acarabixi seja menor quando comparado aos outros lagos. Como o Lago Acarabixi, que possui influência de águas pretas, que são pobres em nutrientes e ácidas, sua produção é reduzida, fazendo com que a proporção de matéria orgânica alóctone seja maior (Lima da Costa 2006). Os eventos observados de intensas taxas de acúmulo para o Lago Acarabixi provavelmente denotam eventos extremos de entrada de material estocado nas extensas planícies aluvionares florestadas do médio Rio Negro. Os lagos de várzeas da Amazônia representam um importante compartimento de retenção de carbono tanto nos dias atuais quanto em épocas passadas. Este comportamento é diretamente relacionado às altas taxas de sedimentação destes ambientes.

Os lagos isolados da dinâmica fluvial apresentam taxas de acumulação de carbono relativamente baixas $\left(<22 \mathrm{~g} \mathrm{~m}^{-2}\right.$ ano). Estas taxas variam em função das características das bacias e dos processos alóctones e autóctones dos sistemas límnicos. As mudanças paleoclimáticas também influenciaram esta acumulação já que interferem diretamente no regime hídrico dos lagos. Os períodos mais secos correspondem a taxas de acumulação de carbono mais baixas sendo que processos de transporte de partículas carbonizadas podem aumentar a deposição de carbono orgânico e influenciar na qualidade da matéria orgânica como observado em Carajás onde se identifica aumento da relação $\mathrm{C} / \mathrm{N}$ durante período de deposição de partículas carbonizadas (Cordeiro et al. 2008). Em Carajás, Cordeiro et al. (2008) observam que as taxas de acumulação de carbono aumentam em função da fase úmida atual, associado a um incremento pronunciado da vegetação macrofítica (Tabela 1, Figura 8).

$\mathrm{O}$ acúmulo de carbono nos lagos fora da dinâmica fluvial dos grandes Rios (ex. Negro e Amazonas) mostram uma relação paleoclimática. Grandes pulsos de acumulação são observados nestes ambientes. Nos três registros obtidos são observadas mudanças climáticas desde o início do Holoceno, principalmente durante o Holoceno médio quando os fluxos de carbono e de partículas biogênicas denotam níveis de lago baixo com ocorrências de incêndios em Carajás e em Roraima. Em Humaitá a sedimentação lacustre inicia-se somente a partir de 4800 anos cal. AP. Provavelmente a fase seca que se observa em Carajás de forma nítida tenha tido influência sobre as demais áreas de estudo alterando fortemente o acúmulo de carbono nos sistemas estudados. No Lago Acarabixi um hiato de sedimentação é observado entre 8200 1500 anos cal. A.P. após um decréscimo substancial nas taxas de acúmulo de carbono. Este hiato de sedimentação coincide com a fase seca pronunciada no médio Holoceno de Carajás e eventos de baixo nível hídrico em Roraima e Humaitá.

Os processos antrópicos aqui representado pelo registro sedimentar obtido em barragem na região de Alta Floresta (MT) mostram que este tipo de sistema é influenciado diretamente pelas mudanças do uso da terra em sua bacia de drenagem tem grande capacidade em acumular carbono.

\section{CONCLUSÃO}

Os lagos amazônicos são hoje produtos da evolução ambiental submetidos em diversas escalas de tempo a flutuações ambientais, outrora governadas por mudanças paleoclimáticas e hoje em dia relacionadas ao sinergismo entre a ação humana e o clima. A dimensão destes eventos é marcada nos registros sedimentares onde o carbono é um importante marcador destas mudanças. Os registros sedimentares de diferentes sistemas límnicos mostram sua susceptibilidade a eventos climáticos e antrópicos quanto à capacidade de acumular carbono no compartimento sedimentar.

Nossos dados revelaram que as várzeas apresentaram maiores fluxos de carbono do que o observado nos lagos isolados da dinâmica fluvial amazônica, o que destaca o papel destes ecossistemas no acumulo de material orgânico, proveniente tanto do Rio quanto da floresta de Terra Firme. Porém, foi determinado, em ambas as várzeas estudadas, que este potencial sofreu alterações ao longo dos últimos milênios, que acompanharam as mudanças paleoclimáticas e paleoambientais ocorridas na região. A acumulação de carbono entre 10580 a 10550 cal. A.P. no lago Acarabixi foi a que apresentou maiores valores chegando a $462 \mathrm{~g} /$ $\mathrm{m}^{2} /$ ano. $\mathrm{O}$ valor de máximo acúmulo encontrado em Acarabixi se apresentou restrito a um breve período de tempo e não apresenta correspondência temporal com os maiores valores encontrados na várzea de Curuaí. 
O valor de taxa de acumulação de carbono encontrado em Acarabixi iguala-se ao maior acúmulo de carbono observado na barragem artificial em área de intensa mudança do uso da terra em Alta Floresta (MT).

Constata-se que para uma real avaliação e estimativa das taxas de acúmulo de carbono em área salagadas na Amazônia deve-se aumentar principalmente a resolução espacial de estudo paleolimnológicos na Amazônia. A compreensão de possíveis interconexões regionais de eventos de acúmulo de carbono associados a mudanças paleoclimáticas e climáticas em sistemas aquáticos continentais deve ser mais bem entendido aumentando a resolução temporal e espacial de estudo de acumulação de carbono.

Tabela I. Concentração e acúmulo de carbono para os sítios estudados sítios estudados em diversas escalas temporais. Table I. Carbon concentration and accumulation in the studied areas over different time scales.

\begin{tabular}{|c|c|c|c|c|}
\hline Lagos/Testemunho & $\begin{array}{l}\text { Escala de tempo } \\
\text { Idade calibrada e } \\
\text { estimada pelo }{ }^{210} \mathrm{~Pb}\end{array}$ & $\begin{array}{l}\text { COT } \\
(\%)\end{array}$ & $\begin{array}{l}\text { Fluxo de } \\
\text { carbono } \\
\text { (g/m²/ano) }\end{array}$ & Interpretação ambiental \\
\hline $\begin{array}{l}\text { Lago Santa Ninha } \\
\text { TA } 11 \\
\text { Sedimentação recente }\end{array}$ & $\sim 100$ anos & 0,83 & 91 & $\begin{array}{l}\text { Alta taxa de sedimentação responsável por uma } \\
\text { alta acumulação de carbono nos últimos anos; }\end{array}$ \\
\hline $\begin{array}{l}\text { Lago Santa Ninha TA14 } \\
\text { Sedimentação milenar }\end{array}$ & $\begin{array}{l}5.700-5100 \\
5100-5000 \\
5000-4000 \\
4000-2300 \\
2300-700 \\
700 \text { até atual }\end{array}$ & $\begin{array}{l}0,9 \\
0,2 \\
0,3 \\
1,2\end{array}$ & $\begin{array}{c}5 \\
1,5 \\
0 \\
3,0\end{array}$ & $\begin{array}{l}\text { Fase úmida com material de origem terrestre } \\
\text { Fase de transição com diminuição do material } \\
\text { orgânico } \\
\text { Fase seca com presença de gramíneas } \\
\text { Fase seca com forte declínio da taxa de } \\
\text { sedimentação } \\
\text { Hiato } \\
\text { Estabilização do clima úmido atual }\end{array}$ \\
\hline $\begin{array}{l}\text { Lago Acarabixi } \\
\text { ACA } 024 \\
\text { Sedimentação recente }\end{array}$ & $\sim 20$ anos & 25 & 265 & $\begin{array}{l}\text { Alta taxa de sedimentação e altos teores de } \\
\text { carbono; responsáveis por uma alta acumulação } \\
\text { de carbono nos últimos anos. }\end{array}$ \\
\hline $\begin{array}{l}\text { Lago Acarabixi } \\
\text { Sedimentação milenar }\end{array}$ & $\begin{array}{c}10620-10580 \\
10580-10550 \\
10550-9700 \\
9700-9600 \\
9600-8200 \\
8200-1500 \\
1500-650\end{array}$ & $\begin{array}{c}0,11 \\
3,11 \\
4,97 \\
13,57 \\
6,46 \\
4,73\end{array}$ & $\begin{array}{l}25,42 \\
462 \\
37,3 \\
138 \\
8,67 \\
0 \\
19,6\end{array}$ & $\begin{array}{l}\text { Estabilidade hídrica; } \\
\text { Pulsos de sedimentação; } \\
\text { Estabilidade hídrica; } \\
\text { Pulso de sedimentação; } \\
\text { Diminuição no regime hidrológico. } \\
\text { Ausência de sedimentação paleoclima mais seco. } \\
\text { Estabilidade hídrica. }\end{array}$ \\
\hline $\begin{array}{l}\text { Lagoa da Pata/ } \\
\text { LPTV }\end{array}$ & $\begin{array}{c}40.000-18.000 \\
25000-18000 \\
18.000 \text { até atual }\end{array}$ & $\begin{array}{l}19,1 \\
6,88 \\
36,0\end{array}$ & $\begin{array}{l}2,19 \\
0,12 \\
4,16\end{array}$ & $\begin{array}{l}\text { Período de descenço no nível hídrico. } \\
\text { Durante o Último Máximo glacial. } \\
\text { Pós-período glacial. }\end{array}$ \\
\hline Carajás/ CSN 933 & $\begin{array}{c}10.000-7000 \\
7450-4750 \\
4750-2800 \\
2800-1300 \\
1300-150 \\
150-\text { atual }\end{array}$ & $\begin{array}{l}6,47 \\
24,6 \\
36,6 \\
46,6 \\
48,9 \\
45,6\end{array}$ & $\begin{array}{l}1,74 \\
6,12 \\
3,90 \\
4,04 \\
10,5 \\
21,3\end{array}$ & $\begin{array}{l}\text { Fase seca com baixo nível hídrico. } \\
\text { Fase seca com ocorrência de incêndios. } \\
\text { Aumento do nível hídrico, incêndios. } \\
\text { Produção lacustre aumenta. } \\
\text { Produção lacustre aumenta. Incêndios. } \\
\text { Fase úmida. Intensa produção macrofítica. }\end{array}$ \\
\hline Humaitá & $\begin{array}{l}4800 \text { a } 4600 \\
4600 \text { a } 4250 \\
4250 \text { a } 3500 \\
3500 \text { a } 400 \\
400 \text { - atual }\end{array}$ & $\begin{array}{l}1,03 \\
5,51 \\
3,58 \\
1,35 \\
5,39\end{array}$ & $\begin{array}{c}3,94 \\
11,27 \\
7,58 \\
1,13 \\
12,65\end{array}$ & $\begin{array}{l}\text { Fase seca com alta ocorrência de incêndios. } \\
\text { Fase úmida com incremento da produtividade. } \\
\text { Fase de transição de intensa atividade erosiva. } \\
\text { Fase seca com pouca ocorrência de incêndios. } \\
\text { Fase úmida com alta ocorrência de incêndios. }\end{array}$ \\
\hline Lago Caracaranã RR94-9 & $\begin{array}{c}11.300-9.400 \\
9.400-8700 \\
8.700-7.600 \\
7.600-6.000 \\
6.000-2.000 \\
2.000 \text { ao atual }\end{array}$ & $\begin{array}{c}1,9 \\
6,1 \\
4,0 \\
5,5 \\
6,1 \\
10,0\end{array}$ & $\begin{array}{l}2,5 \\
10,0 \\
4,5 \\
4,5 \\
3,0 \\
7,5\end{array}$ & $\begin{array}{l}\text { Formação de turfeira com atividade erosiva. } \\
\text { Fase de transição c/ queima da vegetação local. } \\
\text { Fase úmida com incremento da produtividade. } \\
\text { Fase seca com alta ocorrência de incêndios. } \\
\text { Redução da sazonalidade e sem incêndios. } \\
\text { Fase úmida com nível mais alto do lago . }\end{array}$ \\
\hline Alta Floresta & $\begin{array}{l}\text { Início da } \\
\text { colonização. } \\
\text { Lago estabilizado }\end{array}$ & $\begin{array}{c}0,900 \\
6,58 \\
13,4\end{array}$ & $\begin{array}{l}39,6 \\
262 \\
433\end{array}$ & $\begin{array}{l}\text { Início da formação da barragem. } \\
\text { Aumento do nível hídrico da barragem. } \\
\text { Estabilização da barragem. }\end{array}$ \\
\hline
\end{tabular}


AGRADECIMENTOS: Os autores agradecem ao CNPq (Conselho Nacional de Desenvolvimento Científico e Tecnológico) processo 540846/01-5, ao programa de cooperação CNPq-IRD (de Institut Recherche vertem Développemment para le) convenção, CNPq LBA Millenium, a companhia Vale do Rio Doce pelo apóio logistico para o trabalho de campo, e a comissão Executiva de Carbono do INQUA na pessoa de Dr. Louis Scott e Dr. Hughes Faure (In memorium), o IGCP e o projeto nacional francês LEFE-ECHOS.

\section{REFERÊNCIAS}

AB'SABER, A.N. 1977. Espaços Ocupados pela expansão dos climas secos na América do Sul, por ocasião dos periodos glaciais Quaternários. Paleoclimas, 3: 1-19. AB'SABER, A.N. 1986. Geomorfologia da Região de Carajás. p. 88-124. In: J.M.G. Almeida Jr (Org.). Carajás, desafio político, ecologia e desenvolvimento. Brasília: Ed. Brasiliense/CNPq. 633p.

ABSY, M.L.; CLEFF, A.; FOURNIER, M.; MARTIN, L.; SERVANT, M; SIFEDDINE, A.; FERREIRA DA SILVA, M.; SOUBIES, F.; SUGUIO, K.; TURCQ, B \& VAN DER HAMMEN, TH. 1991. Mise en évidence de quatre phases d'ouverture de la forêt dense dans le sud-est de l'Amazonie au cours des 60000 dernières années. Première comparaison avec d'autres régions tropicales. Comptes Rendus de I'academie des Sciences, 312 (2): 673-678.

ADAMS, J.M. \& FAURE, E.H. 1998. A new estimate of changing carbon storage on land since the last glacial maximum, based on global land ecosystem reconstruction. Global and Planetary Change, 16-17: 3-24.

ADAMS, J.M.; FAURE, H. \& FAURE DENARD, L.; McGLADE, J.M. \& WOODWARD, F.I. 1990. Increase in terrestrial carbon storage from the Last Glacial maximum to the present. Nature, 348 (20/27): 711-714.

ALBUQUERQUE, A.L.S. 1998. Paleo-ambientes Holocênicos do Lago Dom Helvecio (Parque Florestal do Rio Doce, Minas Gerais). Tese de doutorado. Universidade Federal Fluminense, Niterói, Brasil. 213p.

BARBOSA, J.A.; CORDEIRO, R.C.; SILVA FILHO, E.V.; TURCQ, B.; GOMES, P.R.O.S; SANTOS, G.; SIFEDDINE, A.; ALBUQUERQUE, A.L.S.; LACERDA, L.D.; HAUSLADEN, P.A.; TIMS, S.G.; LEVCHENKO, V.A. \& FIFIELD, L.K. 2004. ${ }^{14} \mathrm{C}$-AMS as a tool for the investigation of Mercury Deposition at Remote Amazon Location. Nuclear Instruments And Methods In Physics Research B - Beam Interactions With Materials And Atoms, 223-22: 528-534.

BARBOSA, R.I. 1997. Distribuição das chuvas em Roraima. p. 325-335. In: R.I. Barbosa, E.J.G. Ferreira \& E.G. Castellón (Eds.). 1997. Homem, Ambiente e Ecologia no Estado de Roraima. Manaus: INPA, 613p.

BEHLING, H. 2001. Carbon storage increases by major forest ecosystems in tropical South America since the Last Glacial Maximum and the early Holocene. Global and Planetary Change, 33 (1-2):107-116.

BERTAUX, J.; FRÖHLICH, F. \& ILDEFONSE, P. 1998. Multicomponent analysis of FTIR spectra: quantification of amorphous and crystallized mineral phases in synthetic and natural sediments. Journal of Sedimentary Research, 68: 440447.

BIRD, M.I. \& CALI, J.A. A million-year record of fire in subSaharan Africa. Nature, 394:767-769.

BIRD, M.; LLOID, J. \& FARQUHAR, G. 1994. Terrestrial carbon storage at the UMG. Nature, 371: 566-577.

CÂNDIDO, J.L; VOLKMER-RIBEIRO, C.; SIMÕES FILHO, F.F.L.; TURCQ, B. 2000. Analysis of microsclere variations of Dosilia pydanieli (Porifera: Spongillidae) in a lake sediment core. Biociências, 8: 3-12.

CERRI, C.E.P.; EASTER, M.; PAUSTIAN, K.; KILLIAN, K.; COLEMAN, K.; BERNOUX, M.; FALLOON, P.; POWLSON, D.S.; BATJES, N.H.; MILNE, E. \& CERRI, C.C. 2007. Predicted soil organic carbon stocks and changes in the Brazilian Amazon between 2000 and 2030. Agriculture, Ecosystems and Environment, 122: 58-72.

COLINVAUX, P.A.; DE OLIVEIRA, P.E.; MORENO, J.E.; MILLER, M.C. \& BUSH, M.B. 1996. A Long Pollen Record from Lowland Amazonia Forest and Cooling in Glacial Times. Science, 274: 85-88.

CORDEIRO, R.C.; MENDES, L.G.; BARBOSA, J.A.; COSTA, R.L.; TURCQ, B.J.; SIFEDDINE, A.; GIANELLI, A.N. \& NILSSON, L.F.K. 2004. Biogeochemical indicators of environmental changes in Lagoa da Pata during the last 45000 yr BP. 3. In: 2 International Geological Congress. Proceedings of II International Geological Congress. Florença, Itália. Agosto de 2004.

CORDEIRO, R.C.; TURCQ, B.; RIBEIRO JR, M.G.; LACERDA, L.D.; CAPITÂNEO, J.A.; SILVA, A.O.; SIFEDDINE, A. \& TURCQ, P.M. 2002. Forest fires indicators and mercury deposition in an intense land use change region in Brazilian Amazon (Alta Floresta, MT). The Science of Total Environment, 293: 247-253.

CORDEIRO, R.C.; TURCQ,B.; SUGUIO, K.; SILVA, A.O.; SIFEDDINE, A. \& VOLKMER-RIBEIRO, C. 2008. Holocene fires in east Amazonia (Carajás), new evidences, chronology and relation with paleoclimate. Global and Planetary Change, 61: 49-62.

CORDEIRO, R.C. 1995. Mudanças paleoambientais e ocorrência de incêndios nos últimos 7400 anos, na região de Carajás, Pará. Dissertação de mestrado. Universidade Federal Fluminense, Niterói, 144p. 
CORDEIRO, R.C.; TURCQ, B.; OLIVEIRA DA SILVA, A. \& SUGUIO, K. 1997. Holocene environmental changes in Carajás region (Pará, Brazil) recorded by lacustrine deposits. Verh. Internat. Verein. Limnol, 26:814-817.

CROWLEY, T.J. 1995. Ice Age Terrestrial Carbon Changes Revisited. Global Biogeochemical Cycle, 9(3): 377-389.

DEVOL, A.H.; ZARET, T.M. \& FORSBERG, B.R. 1984. Sedimentary organic matter diagenesis and its relation to the carbon budget of tropical Amazon floodplain lakes. Verhandlungen Internationale Vereinigung fu" $r$ theoretische und angewandte. Limnologie, 22: 1299-1304.

DUNNE, T.; MERTES, L.A.K.; MEADE, R.H.; RICHEY, J.E. \& FORSBERG, B.R. 1998. Exchanges of sediment between the flood plain and the channel of the amazon River in Brazil. GSA Bulletin, 110: 450-467.

EINSELE, G.; YAN, J. \& HINDERER, M. 2001. Atmospheric carbon burial in modern lake basins and itssignificance for the global carbon budget. Global and Planetary Change, 30: 167-195.

ELIAS, V.O.; SIMONEIT, B.R.T.; CORDEIRO, R.C. \& TURCQ, B. 2001. Evaluating levoglucosan as an indicator of biomass burning in Carajás, Amazônia: A comparison to the charcoal record. Geochimica et Cosmochimica Acta , 65(2):267-272.

FALESI, I.C. 1986. O ambiente edáfico. p.125-155. In: J.M.G. Almeida Jr (Org.). Carajás, desafio político, ecologia e desenvolvimento. Brasília: Ed. Brasiliense/CNPq. 633p.

FEARNSIDE, P.M. 1987. Causes of deforestation in the Brazilian Amazon. Pp. 37-61. In: R.F. Dickinson (Ed) The Geophysiology of Amazônia: Vegetation and Climate Interactions. John Wiley \& Sons, New York, U.S. 526 pp.

FEARNSIDE, P.M. 1999. Combate ao desmatamento na Amazônia brasileira. Cad.biodivers., 2(2): 35-42.

FGV. 2000. Revista Conjuntura Econômica. jan.:19.

FRÖHLICH, F. 1989. Deep-sea biogenic silica: new structural and analytical data from infrared analysis - geological implications. Terra nova, 1: 267-273.

GOODBRED JR, S.L. \& KUEHL, S.A. 1998. Floodplain processes in the Bengal Basin and the storage of Ganges-Brahmaputra river sediment: an accretion study using $137 \mathrm{Cs}$ and $210 \mathrm{~Pb}$ geochronology. Sedimentary Geology, 121:239-258.

HACON, S. Avaliação do Risco Potencial para a Saúde Humana da Exposição ao Mercúrio na área Urbana de Alta Floresta, Tese Universidade Federal Fluminense. Niterói. RJ. Brazil 1996. $250 \mathrm{pp}$.

HEDGES, J.I.; CLARK, W.A.; QUAY, P.D.; RICHEY, J.E.; DEVOL, A. \& SANTOS, U. 1986. Composition and fluxes of particulate organic material in the Amazon River. Limnology and Oceanography, 31(4): 717-738.
IBGE. 1977. Geografia do Brasil. Grande Região Norte. Rio de Janeiro: Conselho Nacional de Geografia.

INDERMÜHLE, A.; STOCKER, T.F.; FISCHER, H.; SMITH, H.J.; WAHLEN, M.; DECK, B.; MASTROIANNI, D.; TSCHUMI, J.; BLUNIER, T.; MEYER, R. \& STAUFFER, B. 1999. Holocene carbon-cycle dynamics based on $\mathrm{CO}^{2}$ trapped in ice at Taylor Dome, Antartica. Nature, 398:121-126.

JUNK, W.J. 1997. General aspects of floodplain ecology with special reference to amazonian floodplains. In: W.J. Junk (ed.). The Central Amazon floodplain: ecology of a pulsing system, Berlin, Springer: 3-20.

LACERDA, L.D.; RIBEIRO, M.G.; CORDEIRO, R.C.; SIFEDDINE, A. \& TURCQ, B. 1999. Atmospheric Mercury Deposition over Brazil during the past 30,000 years. Ciência e Cultura, Journal of the Brazilian Society for the Advanement of Sciences, 51(5/6): 363-371.

LIM, B. \& CACHIER, H. 1996. Determination of black carbon by chemical oxidation and thermal treatment in recent marine and lake sediments and Cretaceous-Tertiary clays. Chemical Geology, 131: 143-154.

LIMA DA COSTA, R. 2006. Paleohidrologia do Lago Acarabixi, Médio Rio Negro, (AM), durante o Holoceno. Dissertação de mestrado. Universidade Federal Fluminense, Niterói, Brasil.

MARTIN, L.; FLEXOR, J.M. \& SUGUIO, K. 1995. Vibrotestemunhador leve: construção, utilização e potencialidades. Revista do Instituto Geológico, 16: (1/2): 59-66.

MARTINEZ, J.-M. \& TOAN, T. L. 2007. Mapping of flood dynamics and spatial distribution of vegetation in the Amazon floodplain using multitemporal SAR data. Remote Sensing of Environment, 108: 209-223.

MEYERS, P.A. 2003. Applications of organic geochemistry to paleolimnological reconstructions: a summary of exemples from the Laurentian Great Lakes. Organic geochemistry, 34: 261-289.

MEYERS, P.A. 1994. Preservation of elemental and isotopic source identification of sedimentary organic matter. Chemical Geology, 114: 289-302.

MEYERS, P. \& ISHIWATARI, R. 1993. Lacustrine organic geochemistry-an overview of indicators of organic matter sources and diagenisi in lake sediment. Organic. Geochem., 20(7): 867-900.

MOREIRA, L.S. 2008. Reconstrução paleohidrológica do Lago Santa Ninha, Várzea de Curuai, Pará, Brasil. Dissertação de Mestrado. Universidade Federal Fluminense, Niterói. 135 p. MOREIRA-TURCQ, P.; JOUANNEAU, J.M.; TURCQ, B.; SEYLER, P.; WEBER, O. \& GUYOT, J.L. 2004. Carbon sedimentation at Lago Grande de Curuai, a floodplain lake in the low Amazon region: insights into sedimentation rates. 
Palaeogeography, Palaeoclimatology, Palaeoecology, 214(12):.27-40.

MOREIRA-TURCQ, P.; SEYLER, P.; GUYOT, J.L. \& ETCHEBER, H. 2003. Exportation of organic carbon from the amazon River and its main tributaires. Hydrological Process, 17: 1329-1344.

NOBRE, C.A. \& NOBRE, A.D. 2002. O balanço de carbono da Amazônia brasileira. Estud. Av. 16(45): 81-90.

PESSENDA, L.C.R.; VALENCIA, E.P.E.; ARAVENA, R.,; TELLES, E.C.C. \& BOULET, R. 1998. Paleoclimate Studies in Brazil Using Carbon Isotope Studies in Soils. In: J.C. Wasserman, E.V. Silva Filho \& R. Villas-Boas (Eds.). Environmental Geochemistry in the Tropics. R. Springer. $305 \mathrm{p}$.

PETIT, J.R.; JOUZEL, J.; RAYNAUD, D.; BARKOV, N.I.; BARNOLA, J.-M.; BASILE, I.; BENDERS, M.; CHAPPELLAZ， J.; DAVIS, M.; DELAYQUE, G.; DELMOTTE, M.; KOTLYAKOV, V.M.; LEGRAND, M.; LIPENKOV, V.Y.; LORIUS, C.; PÉPIN, L.; RITZ, C.; SALTZMAN, E. \& STIEVENARD, M. 1999. Climate and atmospheric history of the past 420,000 years from the Vostok ice core, Antarctica. Nature, 399: 429-436.

SALDARRIAGA, J. \& WEST, D.C. 1986. Holocene Fires in the Northern Amazon Basin. Quaternary Research, 26: 358366.

SANAIOTTI, T.M. 1997. Comparação fitossociólogica de quatro savanas de Roraima. p. 481-488. In: R.I. Barbosa, E.J.G. Ferreira \& E.G. Castellón (Eds). Homem, Ambiente e Ecologia no Estado de Roraima. Manaus: INPA, 613p. SANFORD, R.L.; SALDARRIAGA, J.; CLARK, K.E.; UHL, K. \& HERRERA, R. 1985. Amazon Rain-Forest Fires. Science, 227(4): 53-55.

SANGER, J.E. \& GORHAM, E. 1972. Statigraphy of fossil pigments as guide to the postglacial history of Kirchner marsh, Minnesota. Lymnology and Oceanography, 17: 840-854.

SANTOS, G.; CORDEIRO, R.C.; SILVA FILHO, E.V.; TURCQ, B.; FIFIELD, L.K.; GOMES, P.R.S.; HAUSLADEN, A. \& SIFEDDINE, A 1999. Chronology of atmospheric mercury in lagoa da pata basin, upper Rio Negro region of Brazilian Amazon. Radiocarbon, 43(2B): 801-808.

SILVA, M.F.F.; SECCO, R.S. \& LOBO, M.G. 1996. Aspectos Ecológicos da Vegetação Rupestre da Serra dos Carajás, Estado do Pará, Brasil. Acta Amazônica, 26(1/2): 17-44.

SIMÕES FILHO, F.F.L. 2000. Sedimentação lacustre $e$ implicações paleoambientais na região de contato florestasavana de Roraima durante o Holoceno. Tese de Doutorado. Universidade Federal Fluminense, Niterói. 213p.
SMITH-MORRILL, L. 1987. The exchange of carbon, nitrogen, and phosphorus between the sediments and water-column of an Amazon floodplain lake. Tese de doutorado, University of Maryland, 209p.

SWAIN, E.B. 1985. Measurement and interpratation of sedimentary pigments. Freshwater Bology, 15: 53-75.

TIAN, H.; MELILLO, J. M.; KICKLIGHTER, D.W.; MCGUIRE, A.D.; HELFRICH III, J.V.K.; MOORE III, B. \& VOROSMARTY, C. 2000. Climatic and biotic controls on annual carbon storage in Amazonian ecosystems. Global Ecology \& Biogeography, 9: 315-335.

TURCQ, B.; CORDEIRO, R.C.; SIFEDDINE, A.; SIMOES FILHO, F.F.; ABRAO, J.J.; OLIVEIRA, F.B.O.; SILVA, A.O.; CAPITANEO, J.L. \& LIMA, F.A K. 2002b. Carbon storage in Amazonia during the UMG: data and uncertainities. Chemosphere, 49: 821-835.

TURCQ, B.; CORDEIRO, R.C.; ALBUQUERQUE, A.L.S.; SIFEDDINE, A.; SIMÕES FILHO, F.F.L.; SOUZA, A.G.; ABRÃO, J.J.; OLIVEIRA, F.B.L.; SILVA, A.O. \& CAPITÂNEO, J.A.. 2002a. Accumulation of organic carbon in five Brazilian lakes during the Holocene. Sedimentary Geology, 148(1-2): 319-342.

TURCQ, B.; SIFEDDINE, A.; MARTIN, L.; ABSY, M.L. \& SOUBIES, F; SUGUIO, K; VOLKMER-RIBEIRO, C. 1998. Amazonian Rainforest fires: A lacustrine record of 7000 Years. Ambio, 27(2): 139-142.

TURCQ, B.; SUGUIO, K.; MARTIN, L. \& FLEXOR, J.M. 1998. Registros milenares nos sedimentos dos lagos da serra de Carajás. Ciência Hoje, 16(93): 31-35.

VAN CAMPO, E.; GUIOT, J. \& PENG, C. 1993. A data-based re-appraisal of terrestrial carbon budget at the last glacial maximum. Global and Planetary Change, 8: 189-201.

Submetido em 08/06/2008. Aceito em 15/08/2008. 